\title{
The elucidation of phospholipid bilayer-small molecule interactions using a combination of phospholipid nanodiscs and solution state NMR techniques
}

Georgina Townshend, Gary S. Thompson, Lisa J. White, Jennifer R. Hiscock* and Jose L. Ortega-Roldan*

\section{Contents}

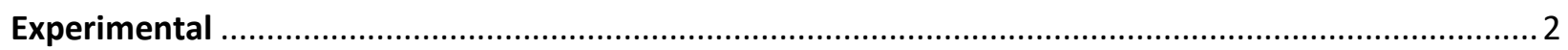

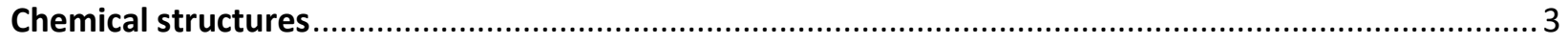

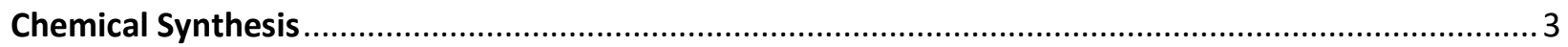

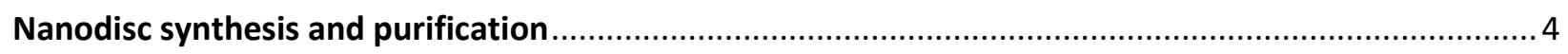

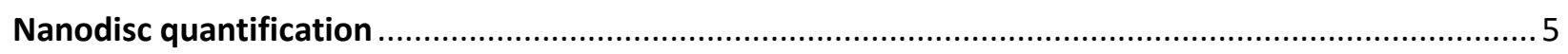

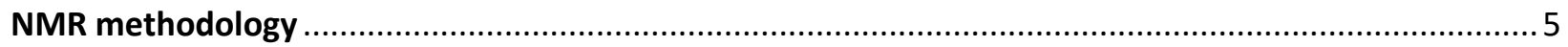

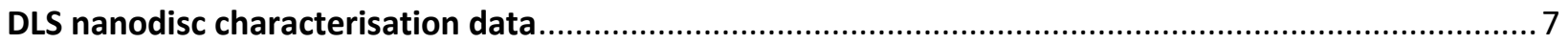

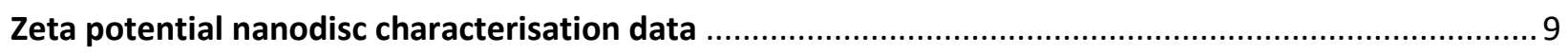

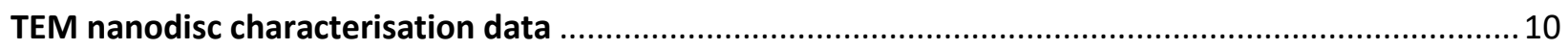

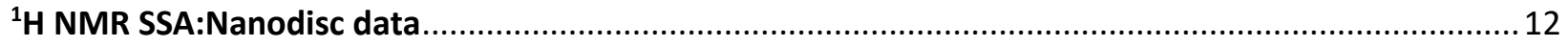

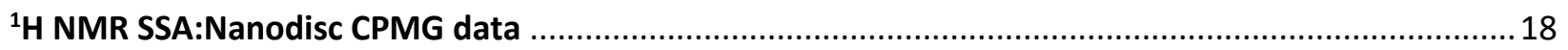

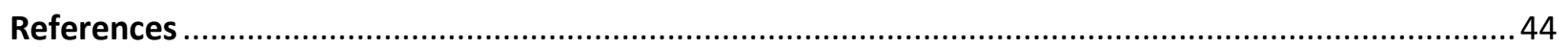




\section{Experimental}

General remarks: A positive pressure of nitrogen and oven dried glassware were used for all reactions. All solvents and starting materials were purchased from known chemical suppliers or available stores and used without any further purification unless specifically stipulated. All phospholipid starting stocks were purchased from Avanti Polar Lipids. The NMR spectra were obtained using a Bruker AV2 $400 \mathrm{MHz}$, Avance III $600 \mathrm{~Hz}$ spectrometer or AVNEO $400 \mathrm{MHz}$ spectrometer. The data was processed using ACD Labs, MestReNova or Topspin software. NMR Chemical shift values are reported in parts per million (ppm) and calibrated to the centre of the residual solvent peak set, unless stated otherwise $(\mathrm{s}=$ singlet, $\mathrm{br}=\mathrm{broad}$, $\mathrm{d}=$ doublet, $\mathrm{t}=$ triplet, $\mathrm{q}=$ quartet, $\mathrm{m}=$ multiplet). Dynamic light scattering (DLS) and Zeta Potential studies were carried out using Anton Paar Litesizer ${ }^{\mathrm{TM}} 500$ and processed using KalliopeTM Professional. TEM images were recorded on a Jeol 1230 TEM, operating at an accelerating voltage of $80 \mathrm{kV}$ equipped with a Gatan One View 16 MP digital camera.

DLS and Zeta Potential Studies: All vials used for preparing the samples were clean and dry. All solvents used were filtered with 0.22 micron filtersremove any particulates that may interfere with the results obtained. A series of 9 or 10 runs were recorded at $25^{\circ} \mathrm{C}$, allowing 10 mins for sample equilibration before the first measurement was recorded. These data were then averaged.

Transmission Electron Microscopy (TEM) Imaging: A droplet $(2 \mu \mathrm{L})$ of sample was applied to formvar/carbon coated 600 mesh copper grids (Agar Scientific) and left for 5 minutes at RT. Excess liquid was aspirated from the grid and a drop of $2 \%$ uranyl acetate (aqueous) was applied to the grid an immediately aspirated. Grids were then dried at room temperature. 


\section{Chemical structures}<smiles>CC(C)COP(=O)(O)OCC[N+](C)(C)C</smiles>

Phosphatidylcholine (PC)<smiles>CC(C)COP(=O)(O[Na])OCC[NH2+]</smiles>

Phosphatidylethanolamine (PE)<smiles>CC(C)COP(=O)(O[Na])OCC(O)CO</smiles>

Phosphatidylglycerol (PG)<smiles>O=C(NCS(=O)(=O)[O-])N1CNc2ccccc2S1</smiles><smiles></smiles>

Figure S1 - Chemical structures of compounds 1-3. TBA = Tetrabutylammonium.

\section{Chemical Synthesis}

Compound 1: This compound was synthesised in line with our previously published methods. Proton NMR were found to match our previously published values. ${ }^{1}{ }^{1} \mathrm{H}$ NMR $\left(400 \mathrm{MHz}, 298 \mathrm{~K}\right.$, DMSO- $\left.d_{6}\right): \delta: 10.67(\mathrm{~s}$, 1H) $8.45(\mathrm{~d}, J=7.77 \mathrm{~Hz}, 1 \mathrm{H}), 8.30(\mathrm{~d}, J=7.79 \mathrm{~Hz}, 1 \mathrm{H}), 8.15(\mathrm{~d}, J=7.92 \mathrm{~Hz}, 1 \mathrm{H}), 7.85(\mathrm{br} \mathrm{s}, \mathrm{d}, J=7.72 \mathrm{~Hz}, 2 \mathrm{H})$, $7.58(\mathrm{t}, J=7.58 \mathrm{~Hz}, 1 \mathrm{H}), 7.47(\mathrm{tt}, J=11.69,7.49 \mathrm{~Hz}, 2 \mathrm{H}), 7.10(\mathrm{t}, J=7.52 \mathrm{~Hz}, 1 \mathrm{H}), 3.96(\mathrm{~s}, 2 \mathrm{H}), 3.23-2.99$ $(\mathrm{m}, 8 \mathrm{H}), 1.62-1.44(\mathrm{~m}, 8 \mathrm{H}), 1.41-1.19(\mathrm{~m}, 8 \mathrm{H}), 0.92(\mathrm{t}, J=7.32 \mathrm{~Hz}, 12 \mathrm{H})$.

Compound 2: This compound was synthesised in line with our previously published methods. Proton NMR were found to match our previously published values. ${ }^{1}{ }^{1} \mathrm{H}$ NMR $\left(400 \mathrm{MHz}, 298 \mathrm{~K}\right.$, DMSO- $\left.d_{6}\right)$ : $\delta: 9.25$ (s, $1 \mathrm{H}), 7.95-7.75(\mathrm{~m}, 4 \mathrm{H}), 7.58(\mathrm{~d}, J=8.74 \mathrm{~Hz}, 2 \mathrm{H}), 7.37-7.20(\mathrm{~m}, 1 \mathrm{H}), 6.98(\mathrm{t}, J=5.88 \mathrm{~Hz}, 1 \mathrm{H}), 3.96(\mathrm{~d}, J=$ $5.88 \mathrm{~Hz}, 2 \mathrm{H}), 3.20-3.01(\mathrm{~m}, 9 \mathrm{H}), 2.43(\mathrm{~s}, 3 \mathrm{H}), 1.63-1.43(\mathrm{~m}, 9 \mathrm{H}), 1.40-1.17(\mathrm{~m}, 9 \mathrm{H}), 0.91(\mathrm{t}, J=7.32 \mathrm{~Hz}$, $12 \mathrm{H})$.

Compound 3: This compound was synthesised in line with our previously published methods. Proton NMR were found to match our previously published values. $\left.{ }^{21} \mathrm{H} \mathrm{NMR} \mathrm{(400} \mathrm{MHz,} 298 \mathrm{~K}, \mathrm{DMSO}-d_{6}\right): \delta: 0.92(\mathrm{t}, J=$ $7.36 \mathrm{~Hz}, 12 \mathrm{H}), 1.25-1.35$ (br m, 8H), $1.52-1.60$ (br m, 8H), $3.14-3.18(\mathrm{br} \mathrm{m}, 8 \mathrm{H}), 3.93(\mathrm{~d}, \mathrm{~J}=5.96 \mathrm{~Hz}, 2 \mathrm{H})$, $6.98(\mathrm{t}, J=5.96 \mathrm{~Hz}, 1 \mathrm{H}), 7.49(\mathrm{~d}, J=9.16 \mathrm{~Hz}, J=8.72 \mathrm{~Hz}, 2 \mathrm{H}), 7.56(\mathrm{~d}, J=8.72 \mathrm{~Hz}, 2 \mathrm{H}), 9.26(\mathrm{~s}, 1 \mathrm{H})$. 


\section{Nanodisc synthesis and purification}

Solubilisation/hydrolysis of Styrene-Maleic Anhydride to produce Styrene-Maleic Acid (SMA): Commercially available styrene-maleic anhydride polymer, with a ratio of 2:1 styrene to maleic anhydride (SMA2000 polymer purchased from Cray Valley via Dr. Timothy Knowles), was first hydrolysed under reflux conditions. Styrene-maleic anhydride anhydride powder $(25 \mathrm{~g})$ was suspended in $\mathrm{NaOH}(250 \mathrm{~mL}$, $1.0 \mathrm{M})$ with anti-bumping granules $(0.1 \mathrm{~g})$ and slowly heated to reflux $\left(100^{\circ} \mathrm{C}\right)$ with constant stirring. The solution was refluxed for $\sim 4$ hours, until all of the solid styrene-maleic anhydride dissolved. Once the solution cooled $\left(20^{\circ} \mathrm{C}\right)$ the SMA was precipitated by reducing the $\mathrm{pH}$ to below 5 with the addition of concentrated $\mathrm{HCl}$ and monitoring the $\mathrm{pH}$ using $\mathrm{pH}$ paper. The precipitated polymer was centrifuged at $11,000 \mathrm{~g}$ for 15 minutes $\left(4^{\circ} \mathrm{C}\right)$, the supernatant was removed and the precipitate was washed with Milli $\mathrm{Q}$ water $(3 \times 250 \mathrm{~mL})$. The polymer was then re-suspended in $\mathrm{NaOH}(0.6 \mathrm{M})$ and adjusted to $\mathrm{pH} 7.4$ and left in an incubator overnight. Once completely solubilised the polymer was lyophilized and stored at room temperature.

Escherichia coli (E.coli) SMA nanodisc preparation: The composition of the total E. coli lipid used in this instance was determined to be $67 \%$ PE, $23.2 \%$ PG and $9.8 \%$ cardiolipin. This lipid composition was determined by Avanti Polar Lipids. E. coli total lipid extract $(10 \mathrm{mg})$ was dissolved in methanol and chloroform (1:1 ratio) and evaporated under a stream of nitrogen, to form a thin lipid film. The resulting lipid film was dried for a further 1 hour under reduced pressure and an inert atmosphere. The lipid film was then hydrated and dispersed in $20 \mathrm{mM}$ sodium phosphate buffer ( $\mathrm{pH}$ 7.4) with $20 \mathrm{mM}$ sodium chloride $(1 \mathrm{~mL})$ using sonication. SMA $(50 \mathrm{mg})$ was added to the opaque lipid solution and incubated for $1 \mathrm{~h}$ at $37^{\circ} \mathrm{C}$, giving a translucent solution.

DMPC SMA nanodisc preparation: 1,2-Dimyristoyl-sn-glycero-3-phosphocholine (DMPC) lipid (10 mg) was dissolved in methanol and chloroform (1:1 ratio) and evaporated under a stream of nitrogen, to form a thin lipid film. The resulting lipid film was dried for a further 1 hour under reduced pressure and an inert atmosphere. The lipid film was then hydrated and dispersed in $20 \mathrm{mM}$ sodium phosphate buffer (pH 7.4) with $20 \mathrm{mM}$ sodium chloride $(1 \mathrm{~mL})$ using sonication. SMA $(50 \mathrm{mg})$ was added to the opaque lipid solution and incubated for $1 \mathrm{~h}$ at $25^{\circ} \mathrm{C}$, giving a translucent solution.

Nanodisc purification: Nanodiscs samples $(1 \mathrm{~mL})$ were centrifuged at $208,000 \mathrm{~g}$ for 30 minutes at $4{ }^{\circ} \mathrm{C}$, the supernatant was collected, and the pellet discarded. The nanodiscs were then dialysed overnight against $4 \mathrm{~L}$ sodium phosphate buffer $(20 \mathrm{mM})$ with $20 \mathrm{mM}$ sodium chloride at $\mathrm{pH} 7.4$ for to remove free SMA with a $50 \mathrm{KDa}$ cut-off dialysis tubing.

The crude nanodisc sample then underwent gel filtration chromatography, where nanodisc samples were concentrated prior to injection and gel filtrated on a Superdex 200 10/300 GL column (GE Healthcare) in the same phosphate buffer ( $\mathrm{pH} 7.4$ ), while monitoring absorbance at $260 \mathrm{~nm}$, to verify the presence of the SMA. This phosphate buffer was used for all the experiments described.

Calculation of Nanodisc refractive index (RI): Nanodiscs were concentrated using a centrifugal concentrator with a $30,000 \mathrm{Da}$ cut-off at $3220 \mathrm{~g}\left(4^{\circ} \mathrm{C}\right)$. The refractive index was determined by taking the average of three samples of nanodiscs, using a manual benchtop refractometer ABBE 5 BS. Hexane was used as a control with a RI 1.375 . 


\section{Nanodisc quantification}

UV-Vis quantification: Quantification of nanodisc concentration was carried out by UV-Vis spectroscopy using a NanodropOne spectrophotometer and known concentrations of the free SMA. Each measurement was repeated 3 times. Calibration was performed prior to use with a control solvent sample, and all spectra were zeroed at $750 \mathrm{~nm}$. The absorbance at $260 \mathrm{~nm}$ was determined plotted in Excel giving a linear calibration curve. This was then used to quantify the concentration of nanodiscs in solution, as a single SMA is responsible for forming a single nanodisc (see manuscript for further details). The linear calibration curve produced from these experimental data is given in Figure S2. The average MW of the hydrolysed polymer was used to calculate the concentrations for the calibration curve.

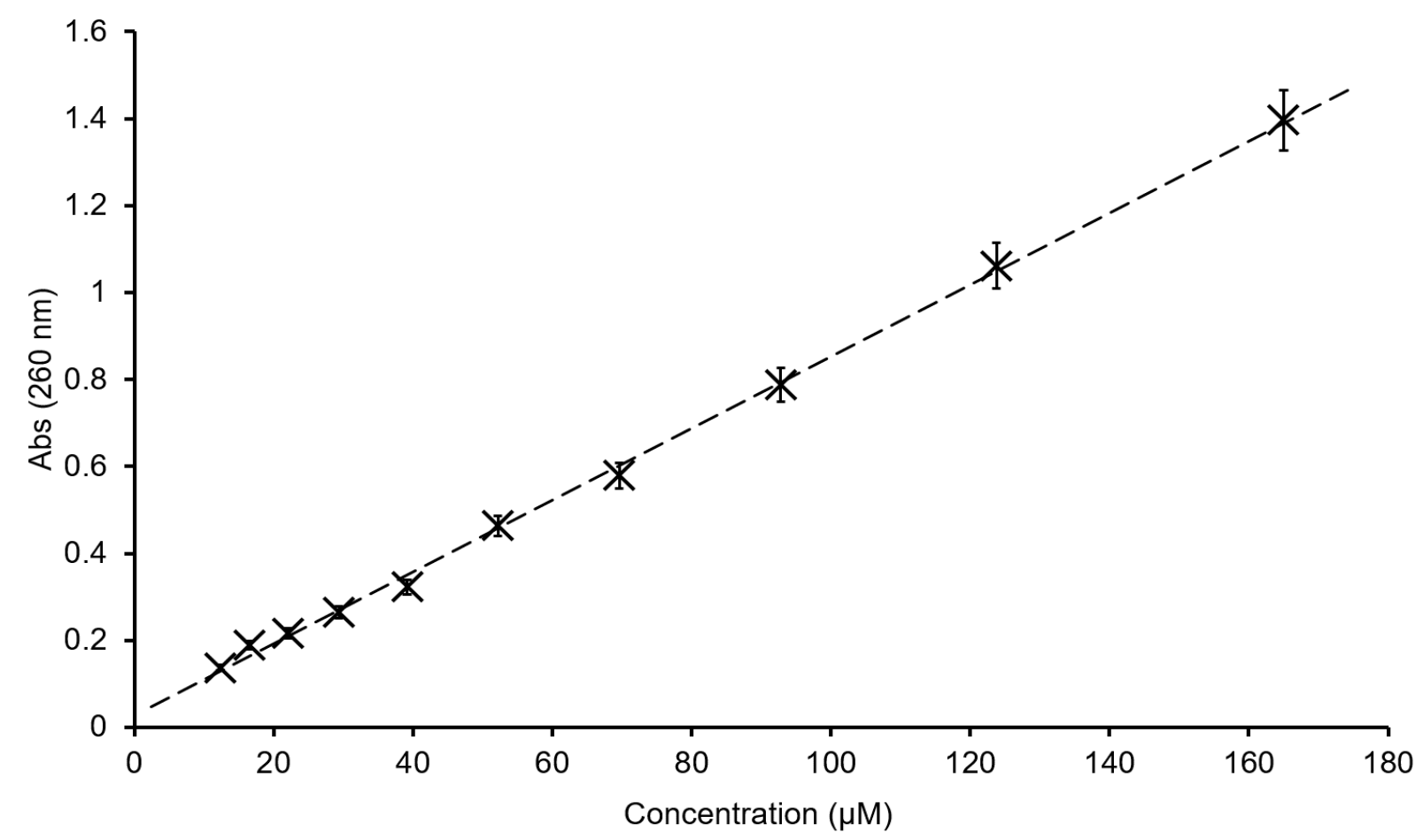

Figure S2 - Calibration curve for SMAs $(n=3)$ in the absence of lipids, monitored by absorbance at $260 \mathrm{~nm}$ (fit $\mathrm{A}_{260}=0.00083$ [SMA $\left.(\mu \mathrm{M})\right]+0.0279 \mathrm{R}=0.9985$ ), in an aqueous phosphate buffered solution $\left(\mathrm{NaH}_{2} \mathrm{PO}_{4}(20 \mathrm{mM}), \mathrm{NaCl}(20 \mathrm{mM})\right.$ at $\left.\mathrm{pH} 7.4\right)$.

\section{NMR methodology}

${ }^{1} \mathrm{H}$ NMR CPMG: ${ }^{1} \mathrm{H}$ NMR CPMG ${ }^{3,4}$ spectra were determined with a Bruker Avance III $600 \mathrm{~Hz}$ spectrometer equipped with a TCIP cryoprobe at $298 \mathrm{~K}$. Samples were supplemented with $5 \% \mathrm{D}_{2} \mathrm{O}$ and $0.01 \mathrm{mM}$ DSS (4,4-dimethyl-4-silapentane-1-sulfonic acid). The standard zgprcpmg pulse sequence from the Bruker library was modified with a watergate element to allow suppression of the water signal was used for all experiments. Although this sequence is readily obtainable, we are happy to provide it on request. The P1 pulses were $9 \mu \mathrm{s}$ at a power of $7.9 \mathrm{~W}$. Presaturation was applied between acquisitions for $100 \mathrm{~ms}$ at a power level of $280 \mathrm{~mW}$ and acquisition was carried out of $0.851 \mathrm{~s}$. Water suppression was achieved with a 3-9-19 watergate sequence using 1 ms pulses with a smoothed chirp shape with a peak strength of 21.2 
G. The CPMG element had a length of $300 \mathrm{~ms}$ with delays between $180^{\circ}$ pulses of $1 \mathrm{~ms}$. Repetition times were chosen to achieve suitable water suppression with the presat and watergate sequences used in a 95 $\% \mathrm{H}_{2} \mathrm{O}$ solution. The length of the CPMG element used was chosen to achieve good differentiation between unbound and strongly bound ligands. Data was collected with 16,384 points and a spectral width of $16.0242 \mathrm{ppm}$, receiver gain was set to 256 , with 128 scans, 16 dummy scans and an acquisition time of $0.85 \mathrm{~s}$. Data was processed using MestreNova software. All spectra were automatically phased, baseline corrected using a polynomial function and calibrated to the centre of the DSS peak. The water signal was suppressed in MestreNova using a convolution method in those experiments with poor water suppression. 


\section{DLS nanodisc characterisation data}

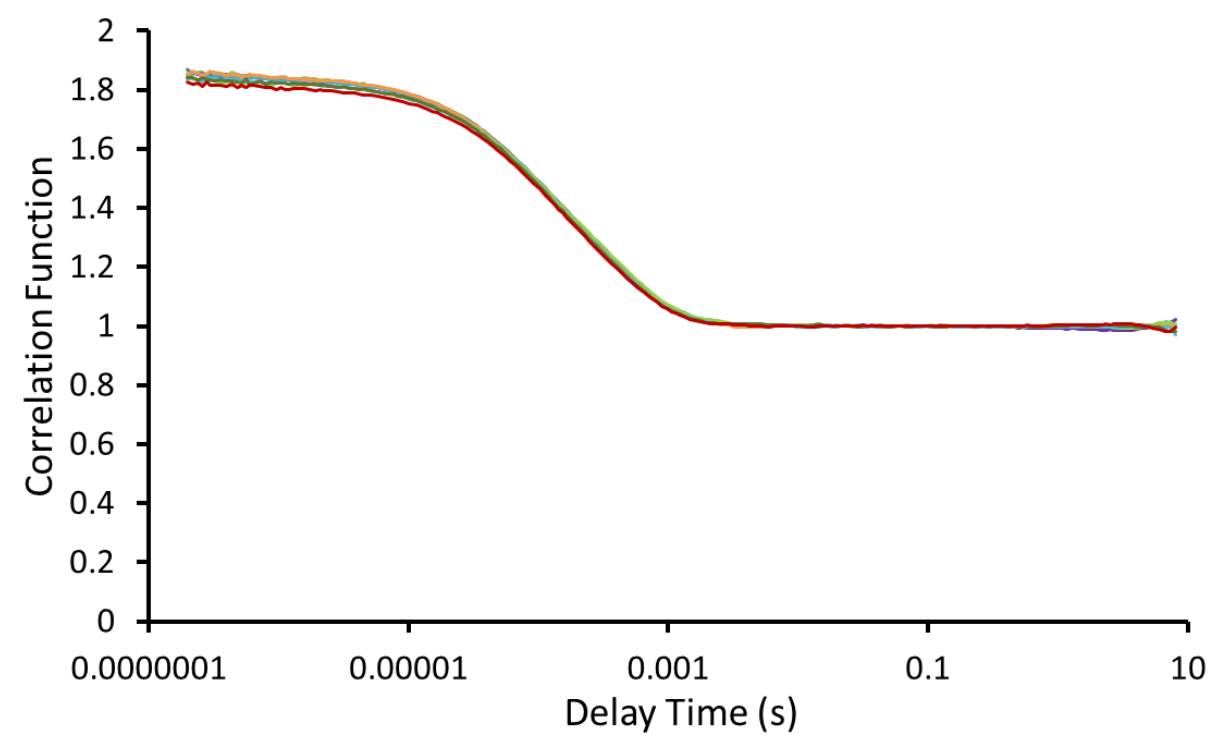

Figure S3 - Correlation function data relating to Figure S4.

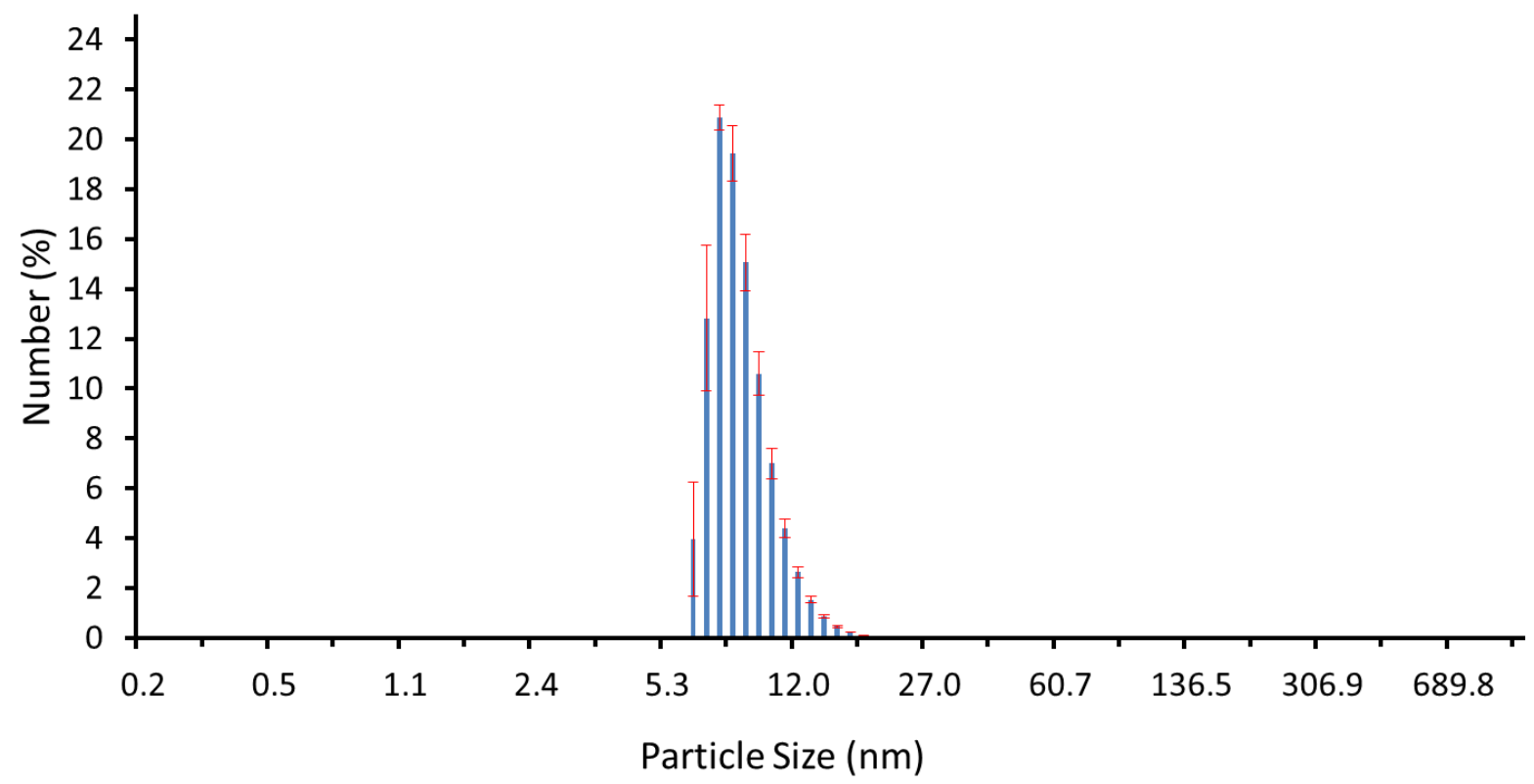

Figure S4 - Average number weighted particle size distribution of $E$. coli SMA nanodiscs (326.6 $\mu \mathrm{M})$, in sodium phosphate buffer $(20 \mathrm{mM})$ with $20 \mathrm{mM}$ sodium chloride at $\mathrm{pH} 7.4$, calculated from 9 DLS runs at $298 \mathrm{~K}$. Error given is the standard error of the mean. 


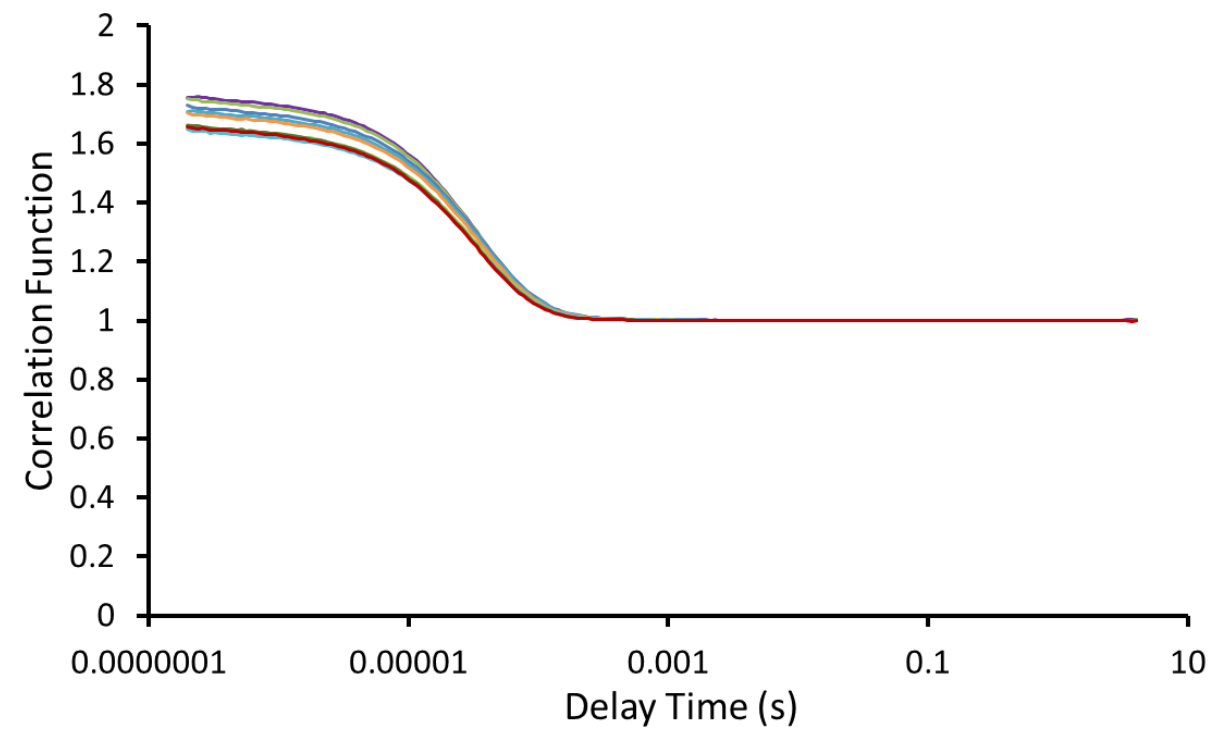

Figure S5 - Correlation function data relating to Figure S6.

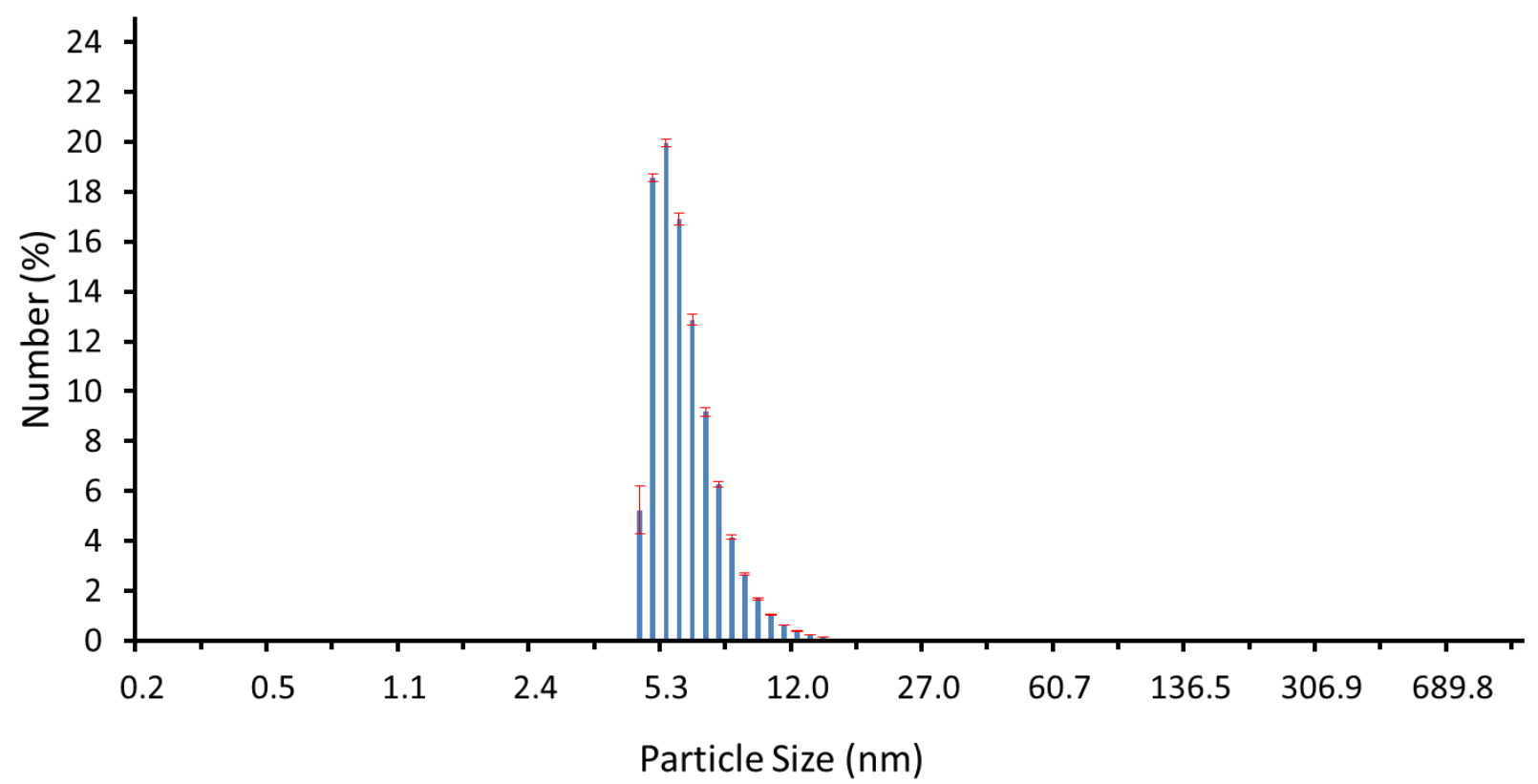

Figure 56 - Average number weighted particle size distribution of DMPC SMA nanodiscs $(412 \mu \mathrm{M})$, in sodium phosphate buffer $(20 \mathrm{mM})$ with $20 \mathrm{mM}$ sodium chloride at $\mathrm{pH} 7.4$, calculated from 9 DLS runs at 298 Error given is the standard error of the mean. 


\section{Zeta potential nanodisc characterisation data}

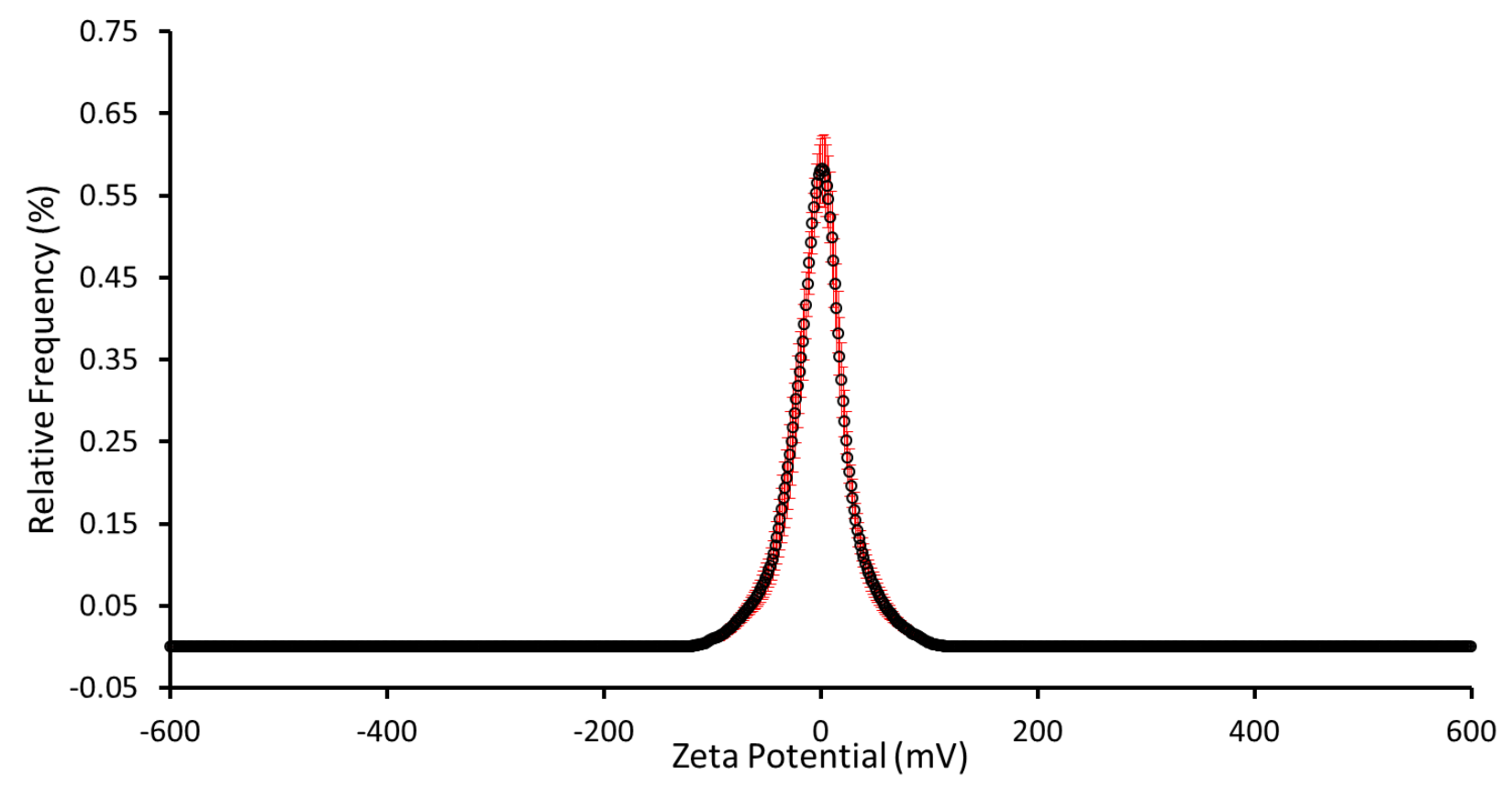

Figure S7 - Zeta potential data for E. coli SMA nanodiscs $(592.9 \mu \mathrm{M})$ in sodium phosphate buffer $(20 \mathrm{mM})$ with $20 \mathrm{mM}$ sodium chloride at pH 7.4, calculated from 10 runs at $298 \mathrm{~K}$, giving a mean average of -20.38 $\mathrm{mV}$. Error given is the standard error of the mean.

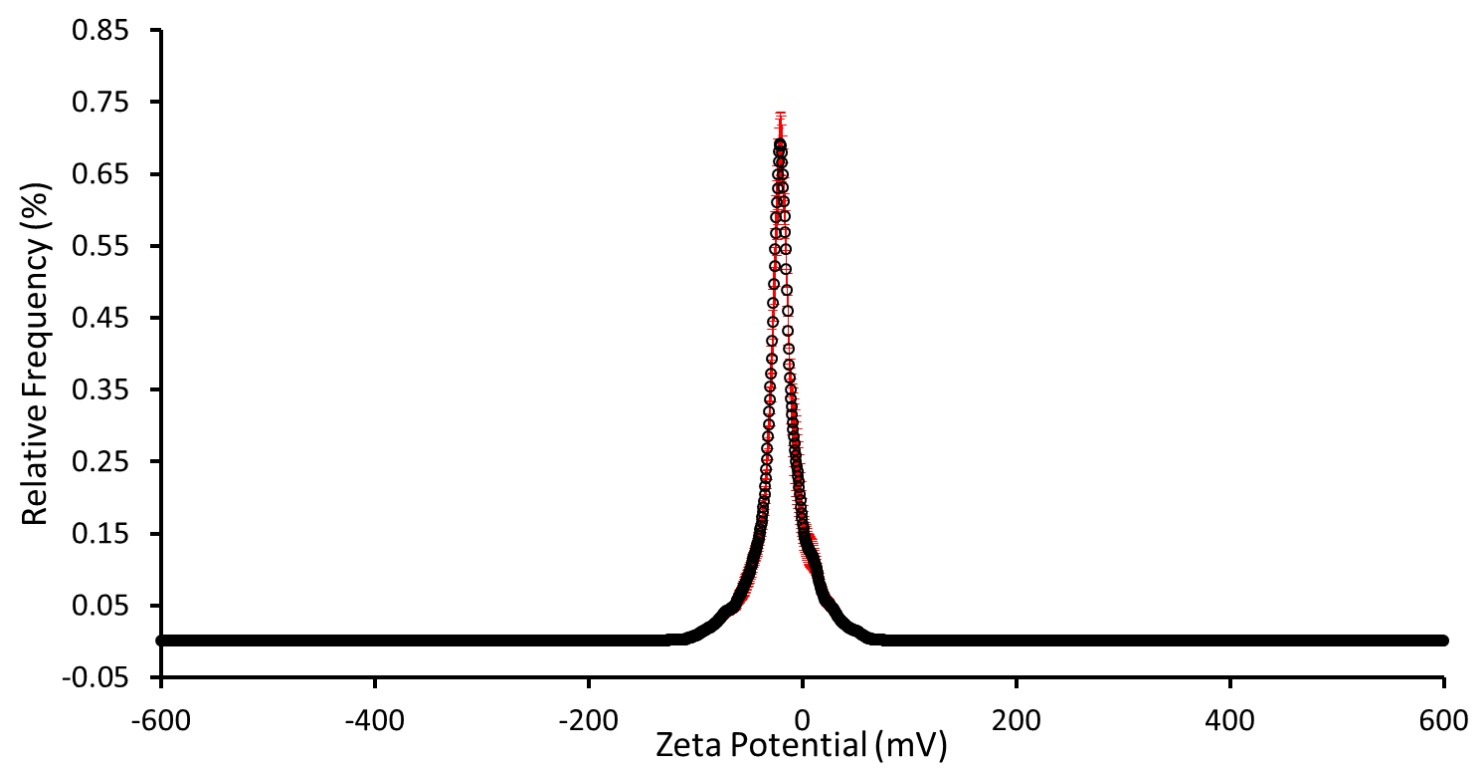

Figure S8 - Zeta potential data for DMPC SMA nanodiscs $(412 \mu \mathrm{M})$ in sodium phosphate buffer (20 mM) with $20 \mathrm{mM}$ sodium chloride at pH 7.4, calculated from 10 runs at $298 \mathrm{~K}$, giving a mean average of -8.50 $\mathrm{mV}$. Error given is the standard error of the mean. 


\section{TEM nanodisc characterisation data}

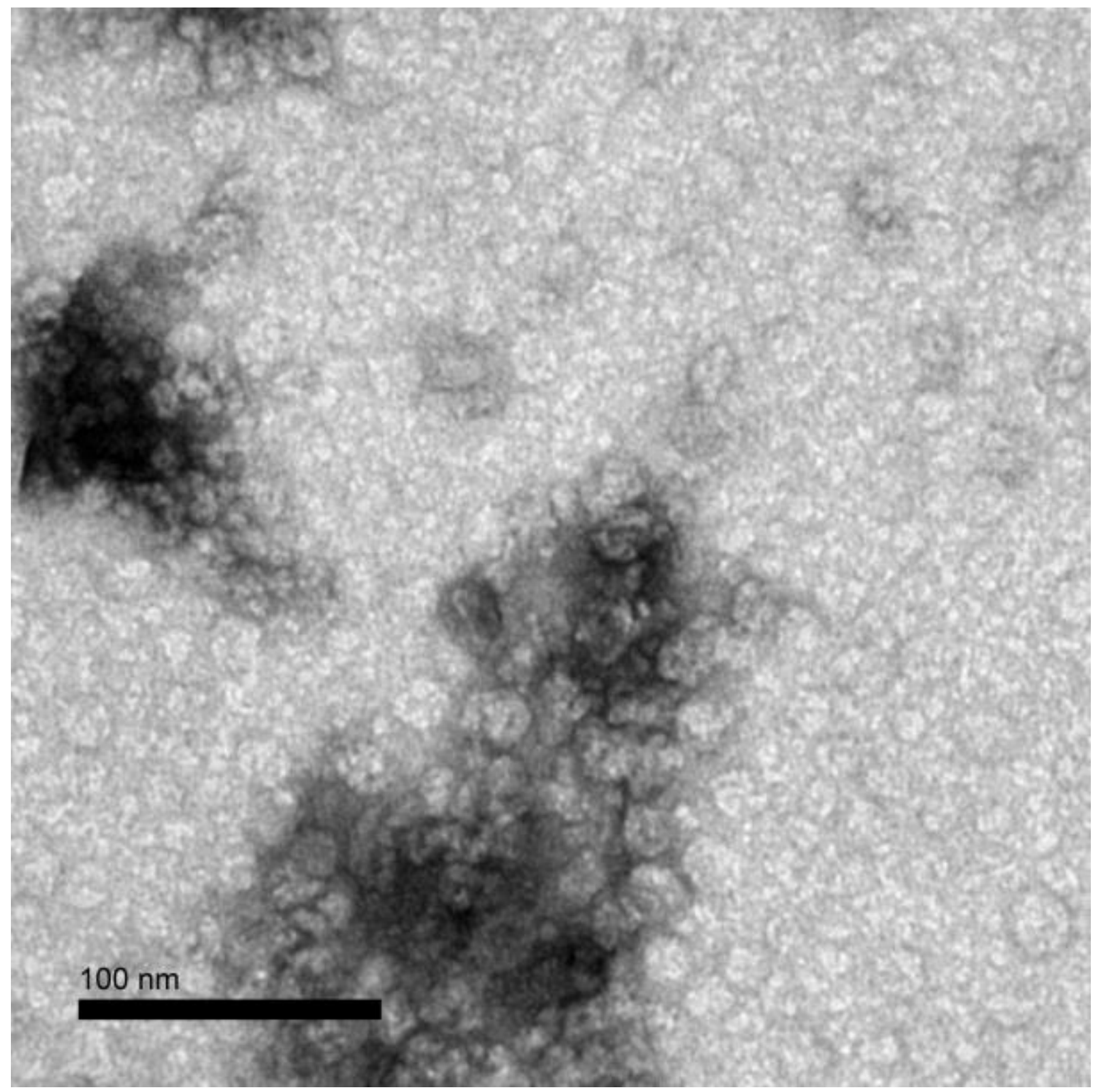

Figure S9 - TEM image of dehydrated E. coli SMA nanodiscs. 


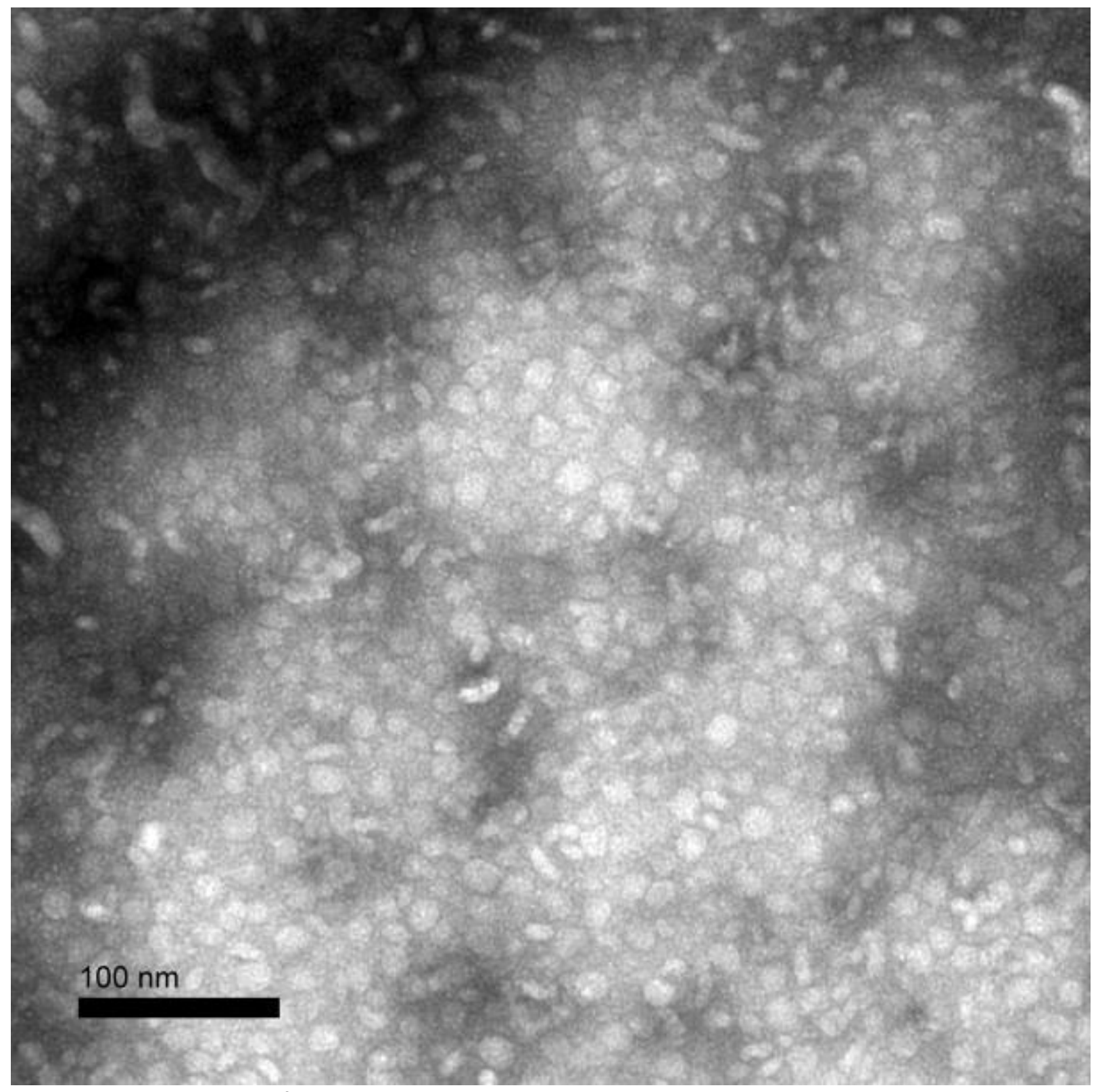

Figure S10 - TEM image of dehydrated DMPC SMA nanodiscs. 


\section{${ }^{1} \mathrm{H}$ NMR SSA:Nanodisc data}

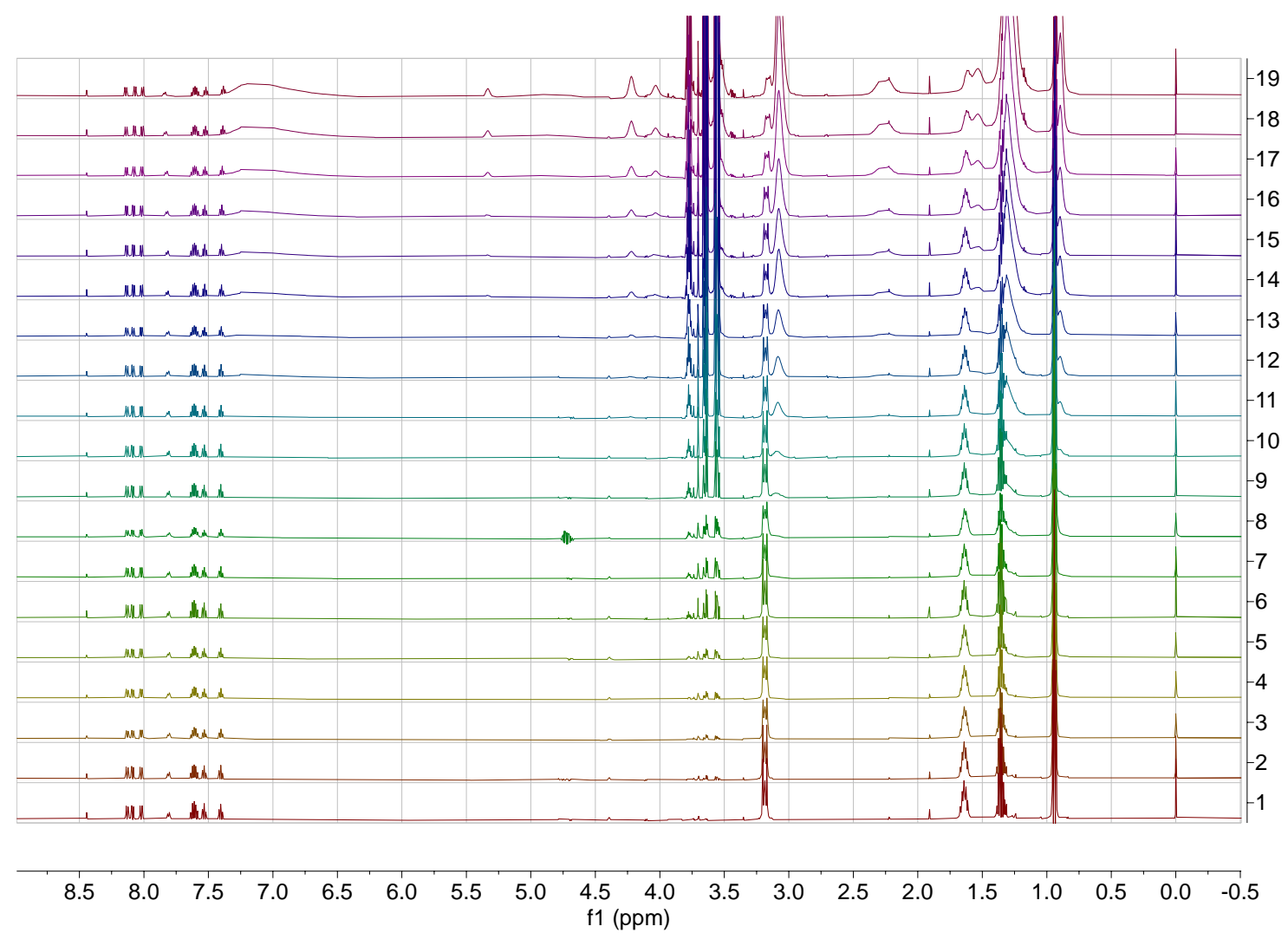

Figure S11 - Stack of $1 \mathrm{D}^{1} \mathrm{H}$ NMR spectrum of 1 at $0.1 \mathrm{mM}$ with increasing concentration of DMPC SMA nanodiscs (SMA nanodisc molar equivalents $=0$ (bottom), 0.002, 0.004, 0.006, 0.008, 0.01, 0.015, 0.02, $0.03,0.04,0.06,0.08,0.1,0.15,0.20,0.25,0.5$ and 1 (top)) in sodium phosphate buffer ( $20 \mathrm{mM}$ ) with 20 $\mathrm{mM}$ sodium chloride at $\mathrm{pH} 7.4$, supplemented with $5 \% \mathrm{D}_{2} \mathrm{O}$ and $0.01 \mathrm{mM}$ DSS. 


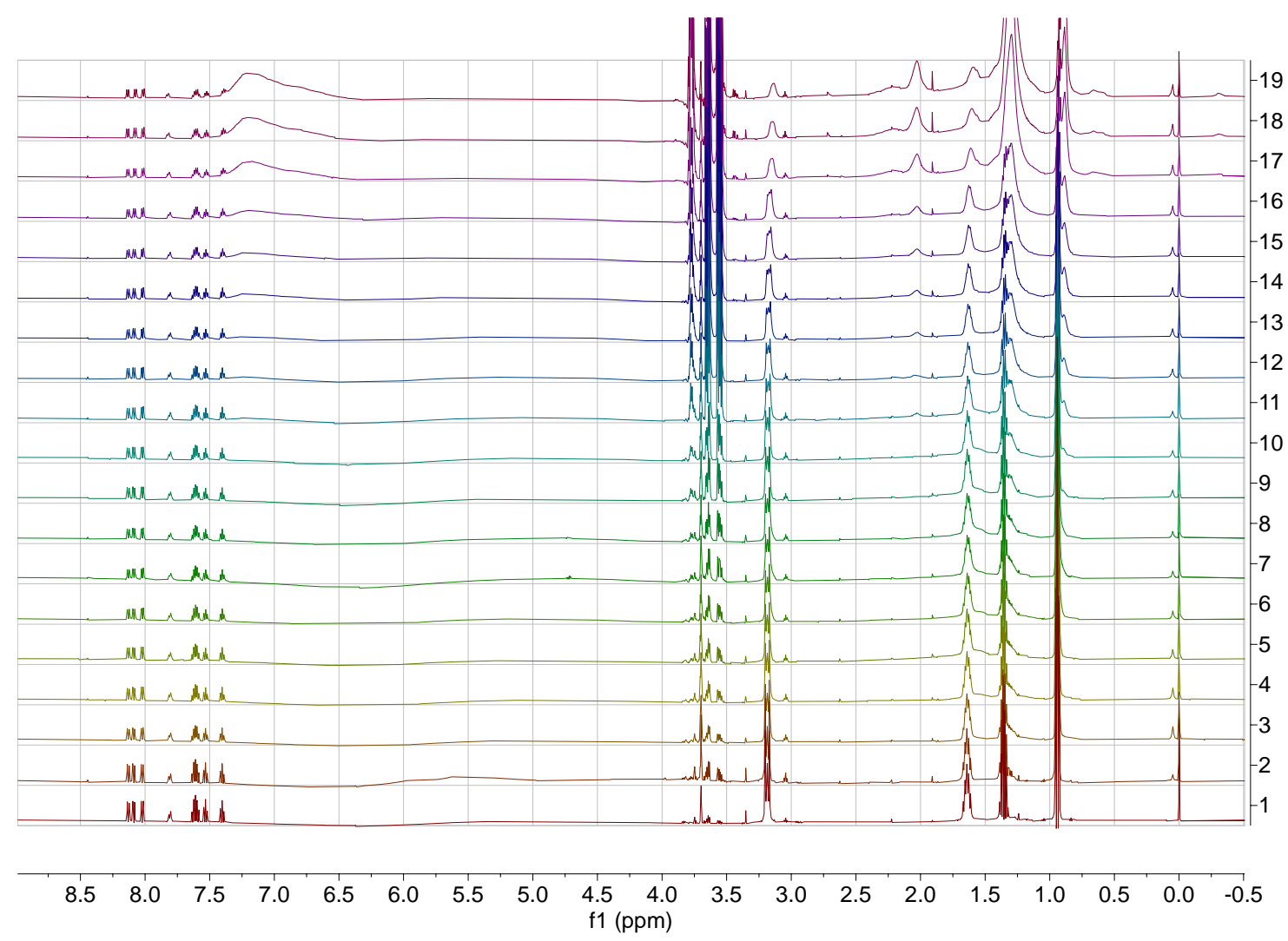

Figure S12 - Stack of 1D ${ }^{1} \mathrm{H}$ NMR spectrum of 1 at $0.1 \mathrm{mM}$ with increasing concentration of $E$. coli SMA nanodiscs (SMA nanodisc molar equivalents $=0$ (bottom), 0.002, 0.004, 0.006, 0.008, 0.01, 0.015, 0.02, $0.03,0.04,0.06,0.08,0.1,0.15,0.20,0.25,0.5$ and 1 (top)) in sodium phosphate buffer ( $20 \mathrm{mM}$ ) with 20 $\mathrm{mM}$ sodium chloride at $\mathrm{pH} 7.4$, supplemented with $5 \% \mathrm{D}_{2} \mathrm{O}$ and $0.01 \mathrm{mM}$ DSS. 


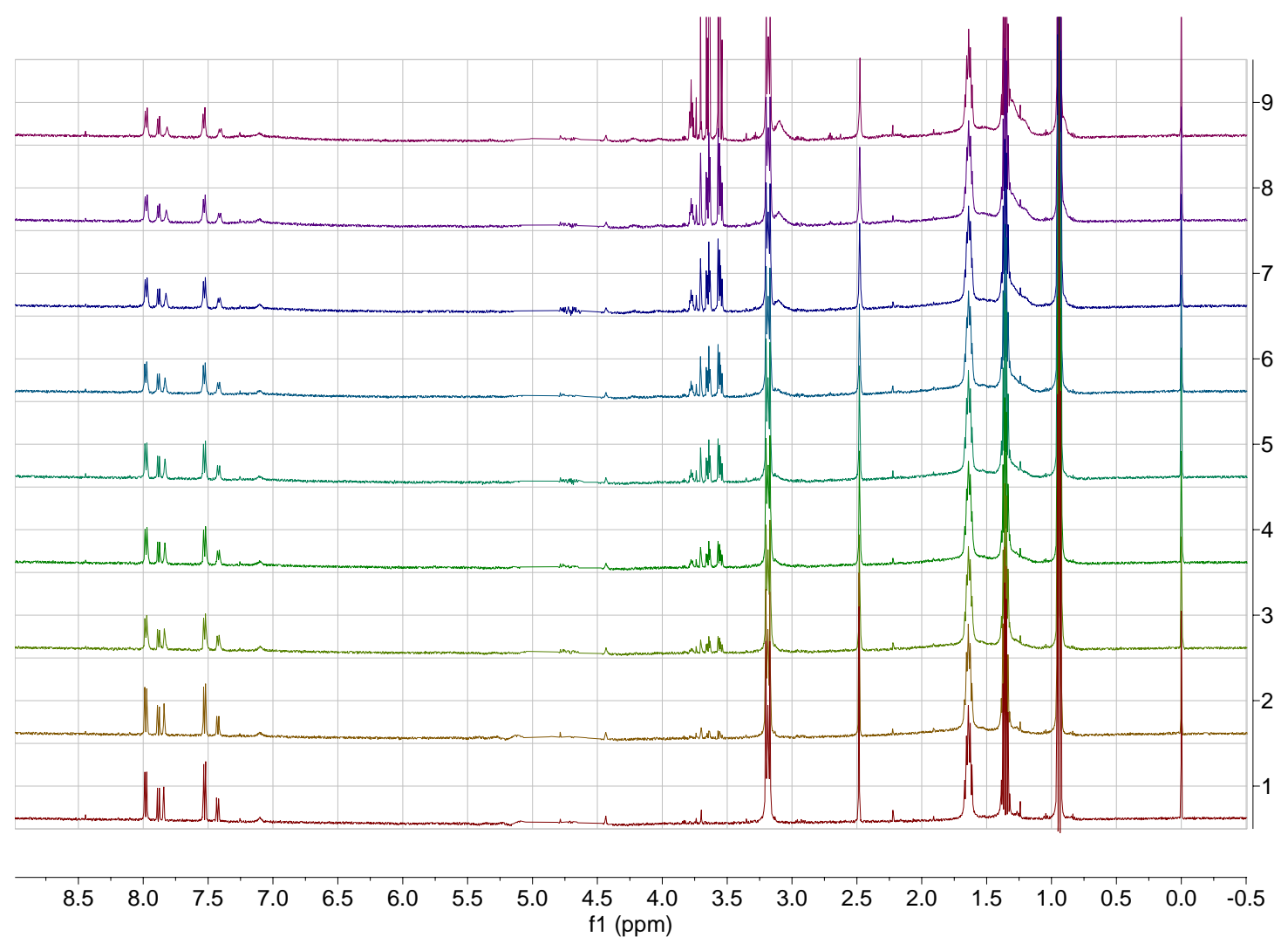

Figure S13 - Stack of 1D ${ }^{1} \mathrm{H}$ NMR spectrum of 2 at $0.1 \mathrm{mM}$ with increasing concentration of DMPC SMA nanodiscs (SMA nanodisc molar equivalents $=0$ (bottom), 0.002, 0.004, 0.006, 0.008, 0.01, 0.015, 0.021, 0.032 , (top)) in sodium phosphate buffer $(20 \mathrm{mM}$ ) with $20 \mathrm{mM}$ sodium chloride at $\mathrm{pH} 7.4$, supplemented with $5 \% \mathrm{D}_{2} \mathrm{O}$ and $0.01 \mathrm{mM}$ DSS. 


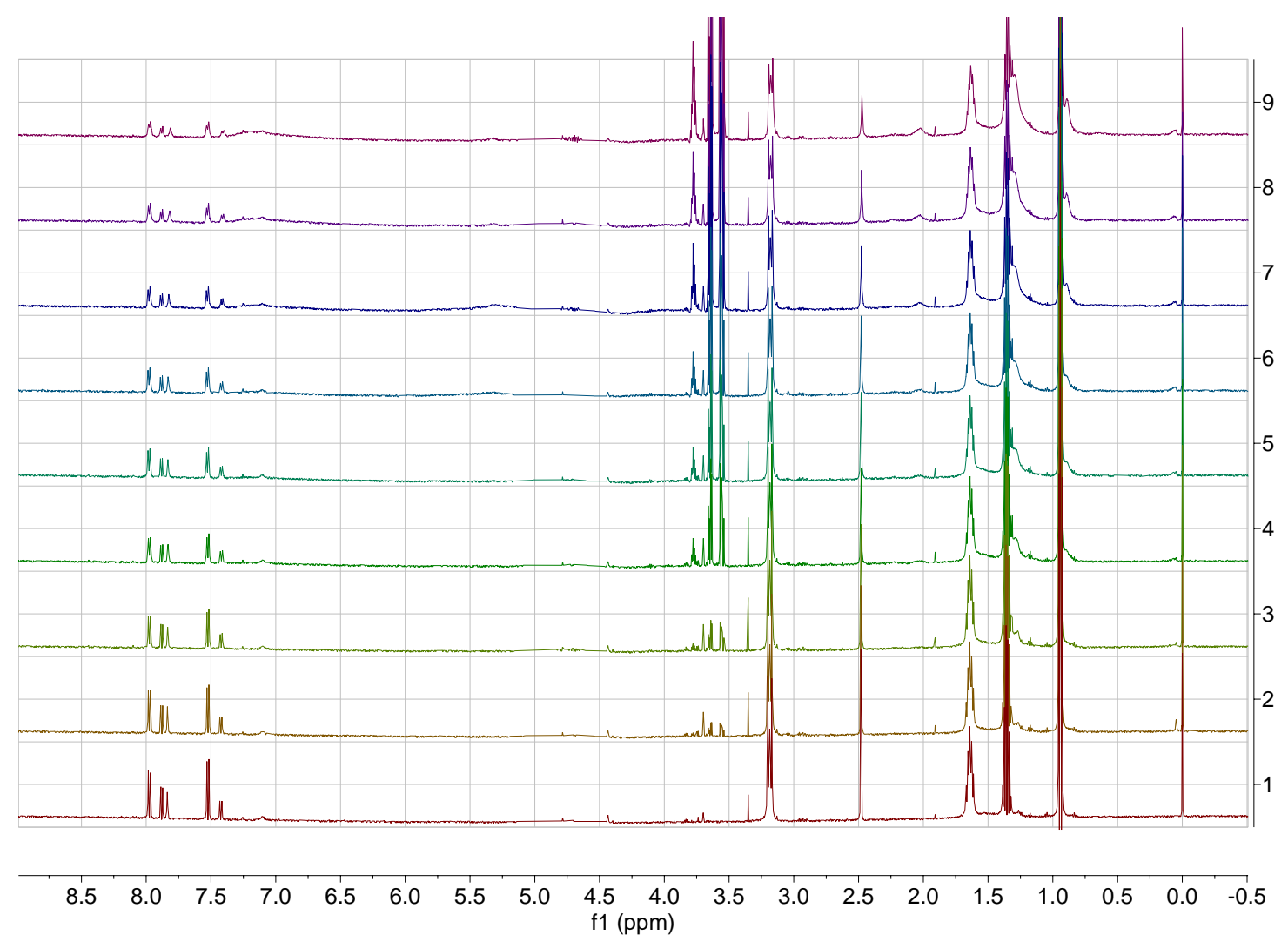

Figure S14 - Stack of $1 \mathrm{D}^{1} \mathrm{H}$ NMR spectrum of 2 at $0.1 \mathrm{mM}$ with increasing concentration of $E$. coli SMA nanodiscs (SMA nanodisc molar equivalents $=0$ (bottom), 0.002, 0.004, 0.006, 0.008, 0.01, 0.015, 0.021, 0.032 , (top)) in sodium phosphate buffer $(20 \mathrm{mM})$ with $20 \mathrm{mM}$ sodium chloride at $\mathrm{pH} 7.4$, supplemented with $5 \% \mathrm{D}_{2} \mathrm{O}$ and $0.01 \mathrm{mM}$ DSS. 


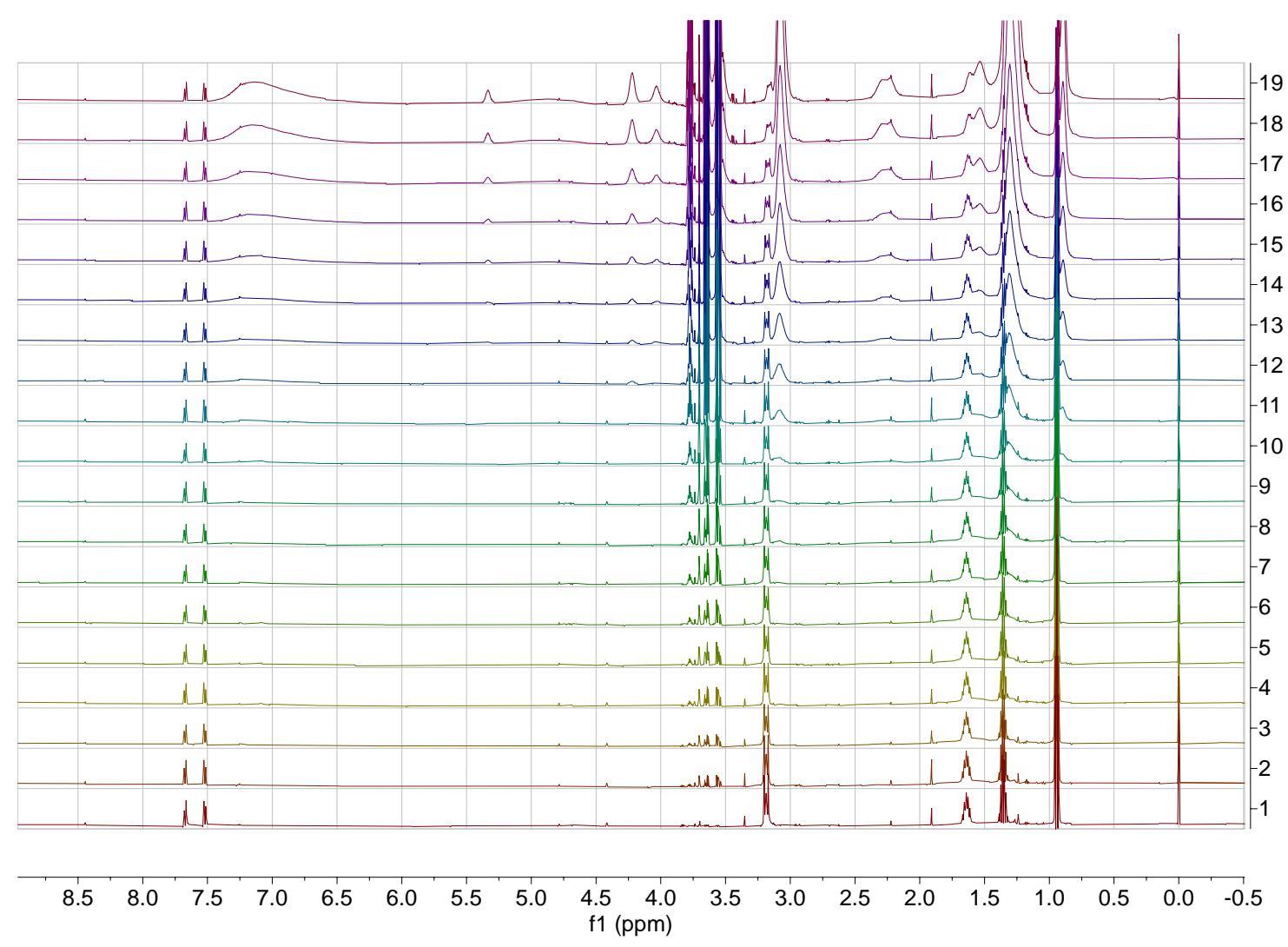

Figure S15 - Stack of 1D ${ }^{1} \mathrm{H}$ NMR spectrum of 3 at $0.1 \mathrm{mM}$ with increasing concentration of DMPC SMA nanodiscs (SMA nanodisc molar equivalents $=0$ (bottom), 0.002, 0.004, 0.006, 0.008, 0.01, 0.015, 0.021, $0.032, .043,0.064,0.086,0.108,0.163,0.219,0.276,0.572,0.890,1.229$ (top)) in sodium phosphate buffer $(20 \mathrm{mM})$ with $20 \mathrm{mM}$ sodium chloride at $\mathrm{pH} 7.4$, supplemented with $5 \% \mathrm{D}_{2} \mathrm{O}$ and $0.01 \mathrm{mM}$ DSS. 


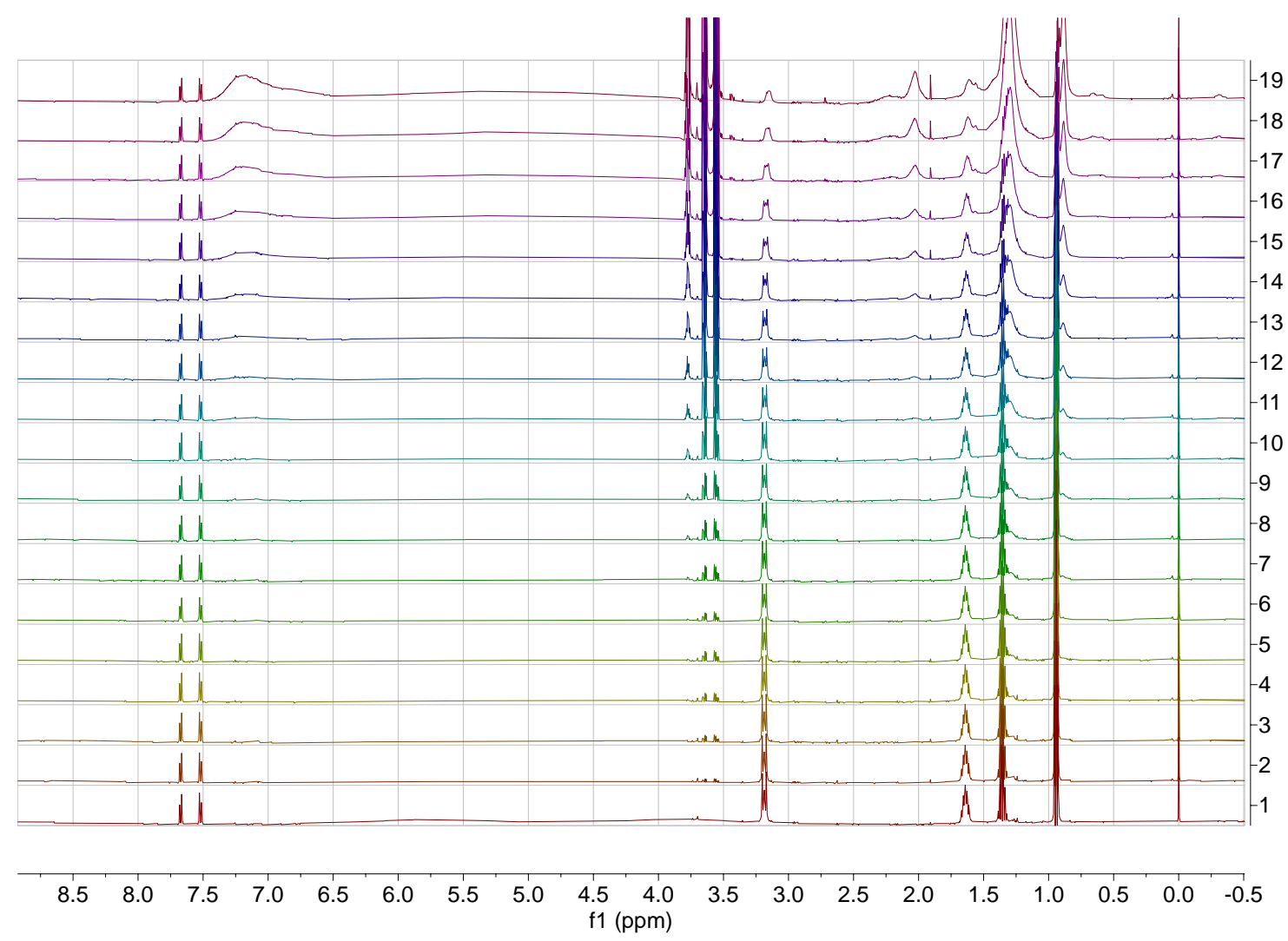

Figure S16 - Stack of $1 \mathrm{D}^{1} \mathrm{H}$ NMR spectrum of 3 at $0.1 \mathrm{mM}$ with increasing concentration of $E$. coli SMA nanodiscs (SMA nanodisc molar equivalents $=0$ (bottom), 0.002, 0.004, 0.006, 0.008, 0.01, 0.015, 0.021, $0.032, .043,0.064,0.086,0.108,0.163,0.219,0.276,0.572,0.890,1.229$ (top)) in sodium phosphate buffer $(20 \mathrm{mM})$ with $20 \mathrm{mM}$ sodium chloride at $\mathrm{pH} 7.4$, supplemented with $5 \% \mathrm{D}_{2} \mathrm{O}$ and $0.01 \mathrm{mM}$ DSS. 


\section{${ }^{1}$ H NMR SSA:Nanodisc CPMG data}

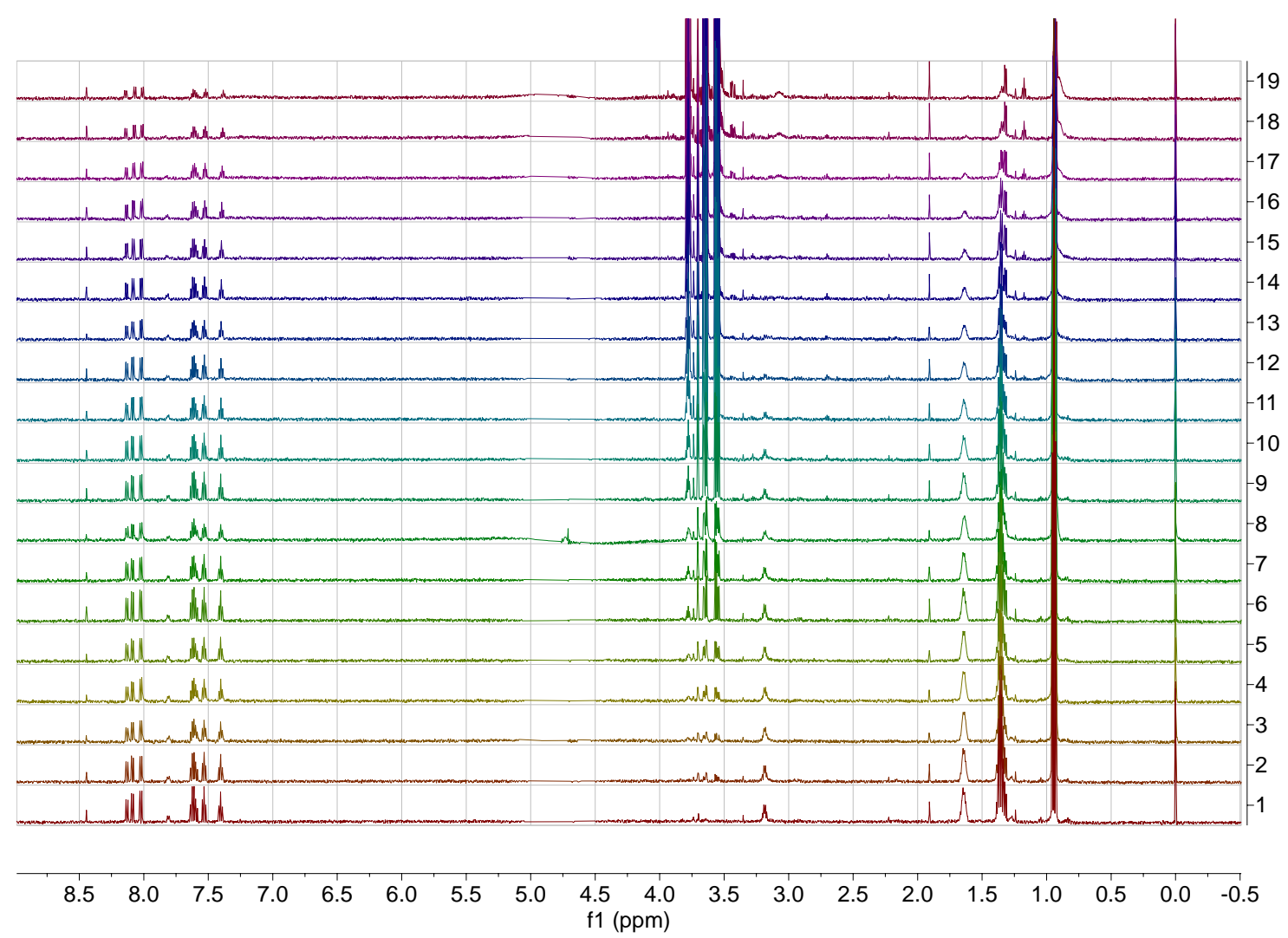

Figure S17 - Stack of $1 \mathrm{D}^{1} \mathrm{H}$ CPMG NMR spectrum of 1 at $0.1 \mathrm{mM}$ with increasing concentration of DMPC SMA nanodiscs (SMA nanodisc molar equivalents $=0$ (bottom), 0.002, 0.004, 0.006, 0.008, 0.01, 0.015, $0.02,0.03,0.04,0.06,0.08,0.1,0.15,0.20,0.25,0.5$ and 1 (top)) in sodium phosphate buffer ( $20 \mathrm{mM}$ ) with $20 \mathrm{mM}$ sodium chloride at $\mathrm{pH} 7.4$, supplemented with $5 \% \mathrm{D}_{2} \mathrm{O}$ and $0.01 \mathrm{mM}$ DSS. 


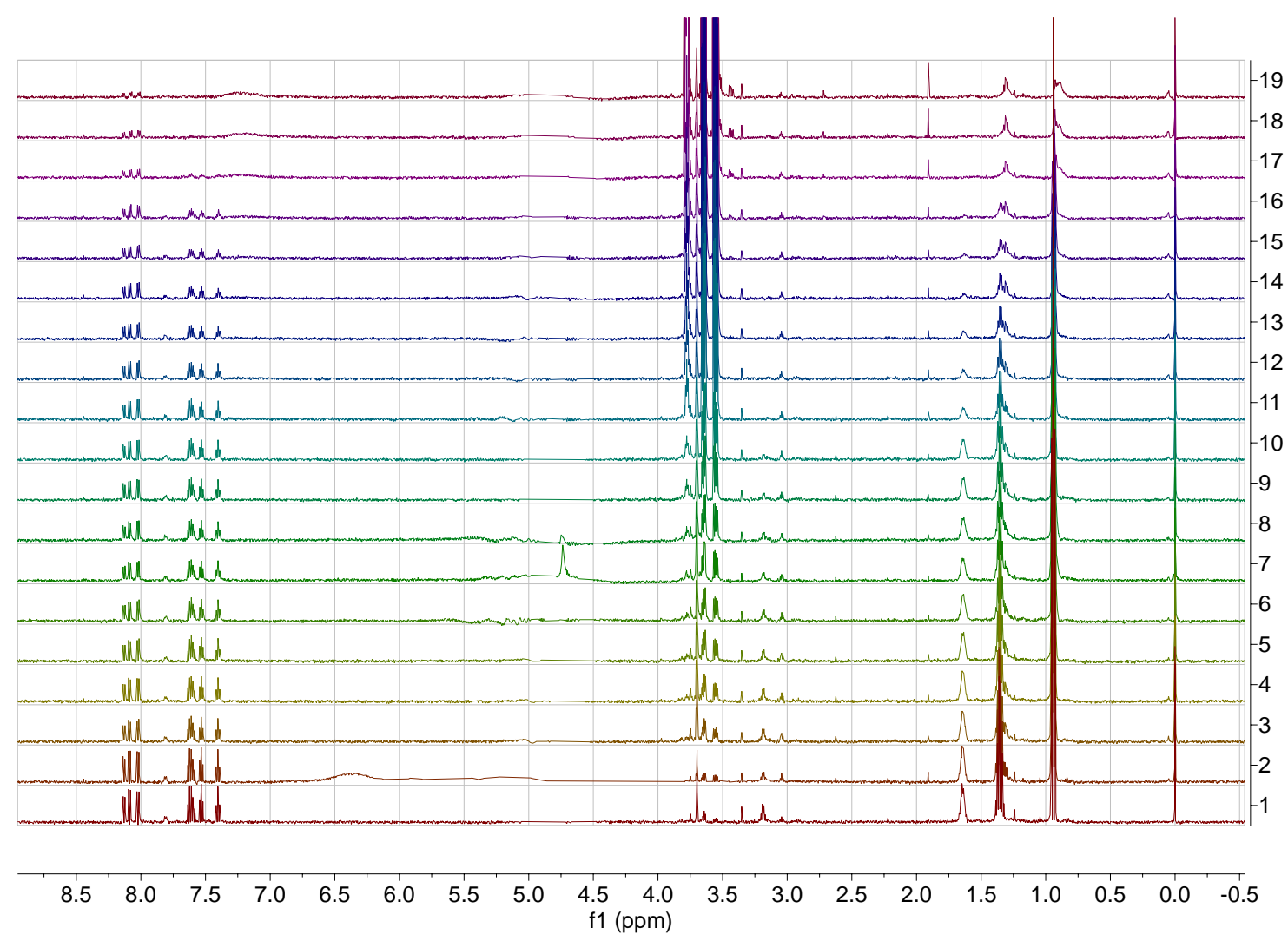

Figure S18 - Stack of 1D ${ }^{1} \mathrm{H}$ CPMG NMR spectrum of 1 at $0.1 \mathrm{mM}$ with increasing concentration of $E$. coli SMA nanodiscs (SMA nanodisc molar equivalents $=0$ (bottom), 0.002, 0.004, 0.006, 0.008, 0.01, 0.015, $0.02,0.03,0.04,0.06,0.08,0.1,0.15,0.20,0.25,0.5$ and 1 (top)) in sodium phosphate buffer (20 mM) with $20 \mathrm{mM}$ sodium chloride at $\mathrm{pH} 7.4$, supplemented with $5 \% \mathrm{D}_{2} \mathrm{O}$ and $0.01 \mathrm{mM}$ DSS. 


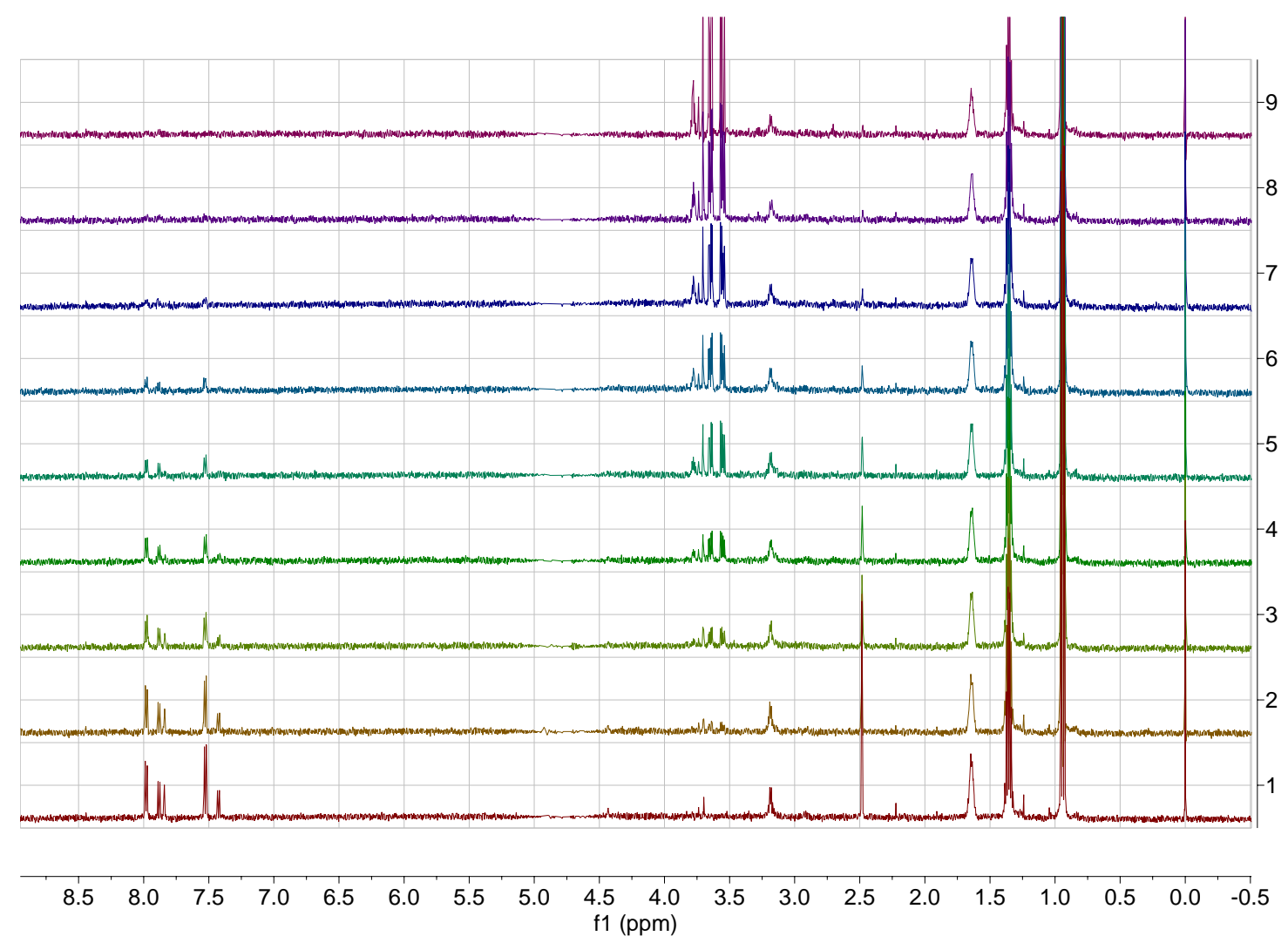

Figure S19 - Stack of 1D ${ }^{1} \mathrm{H}$ CPMG NMR spectrum of 2 at $0.1 \mathrm{mM}$ with increasing concentration of DMPC SMA nanodiscs (SMA nanodisc molar equivalents $=0$ (bottom), 0.002, 0.004, 0.006, 0.008, 0.01, 0.015, $0.021,0.032$, (top)) in sodium phosphate buffer $(20 \mathrm{mM})$ with $20 \mathrm{mM}$ sodium chloride at $\mathrm{pH} 7.4$, supplemented with $5 \% \mathrm{D}_{2} \mathrm{O}$ and $0.01 \mathrm{mM}$ DSS. 


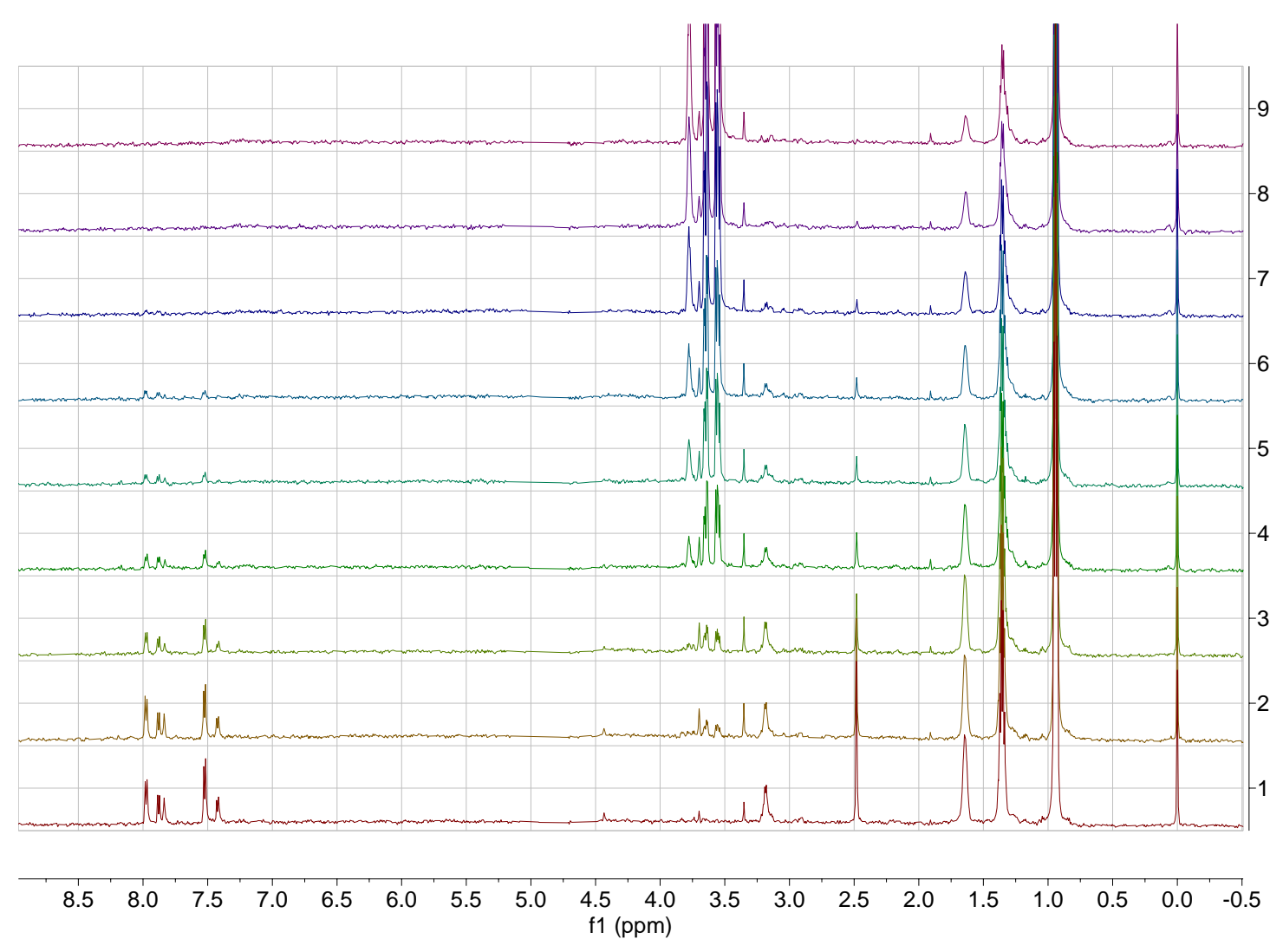

Figure S20 - Stack of $1 \mathrm{D}^{1} \mathrm{H}$ CPMG NMR spectrum of 2 at $0.1 \mathrm{mM}$ with increasing concentration of $E$. coli SMA nanodiscs (SMA nanodisc molar equivalents = 0 (bottom), 0.002, 0.004, 0.006, 0.008, 0.01, 0.015, $0.021,0.032$, (top)) in sodium phosphate buffer $(20 \mathrm{mM})$ with $20 \mathrm{mM}$ sodium chloride at $\mathrm{pH} 7.4$, supplemented with $5 \% \mathrm{D}_{2} \mathrm{O}$ and $0.01 \mathrm{mM}$ DSS. 


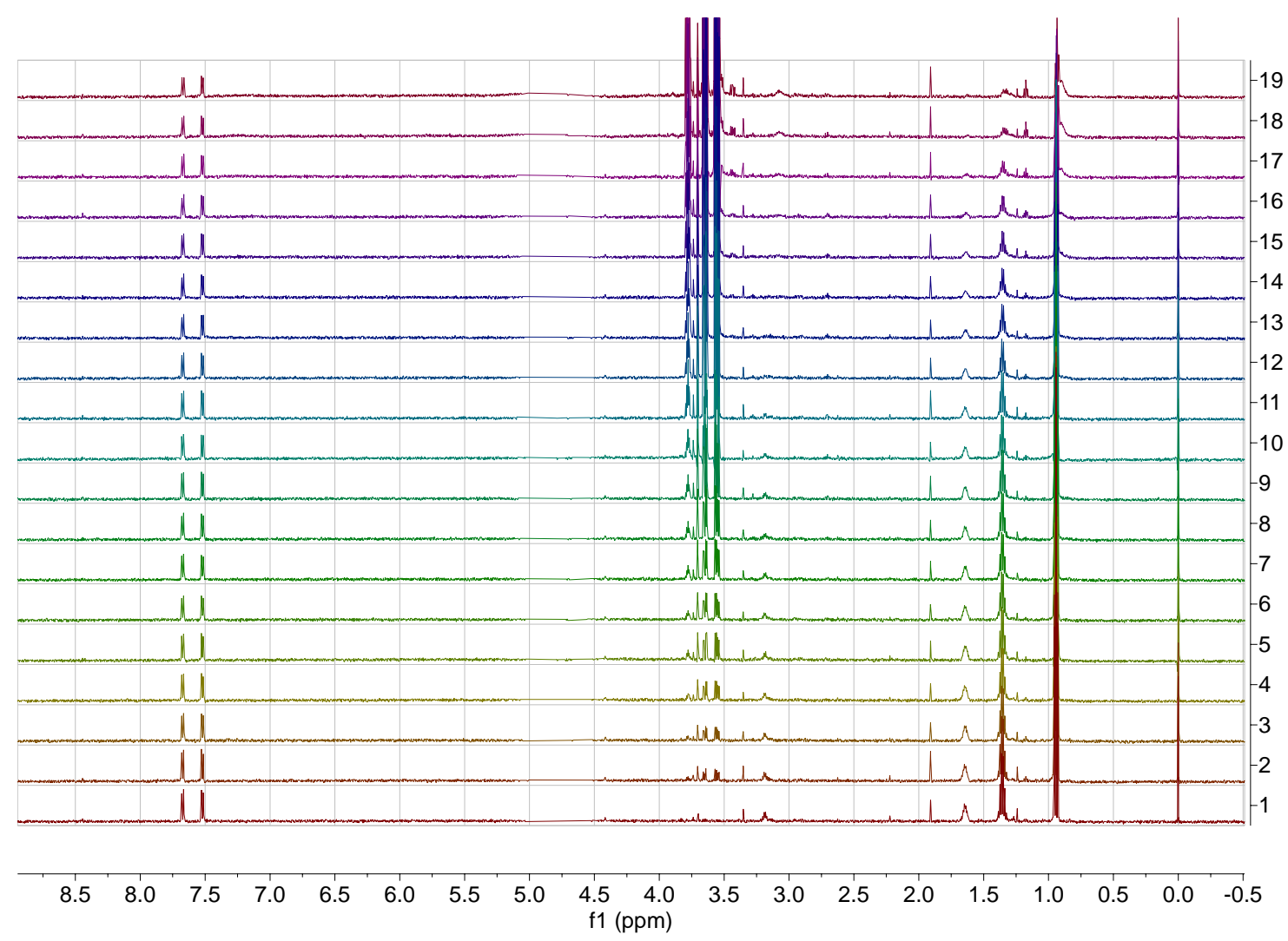

Figure S21 - Stack of $1 \mathrm{D}^{1} \mathrm{H}$ CPMG NMR spectrum of 3 at $0.1 \mathrm{mM}$ with increasing concentration of DMPC SMA nanodiscs (SMA nanodisc molar equivalents $=0$ (bottom), 0.002, 0.004, 0.006, 0.008, 0.01, 0.015, $0.021,0.032, .043,0.064,0.086,0.108,0.163,0.219,0.276,0.572,0.890,1.229$ (top)) in sodium phosphate buffer $\left(20 \mathrm{mM}\right.$ ) with $20 \mathrm{mM}$ sodium chloride at $\mathrm{pH} 7.4$, supplemented with $5 \% \mathrm{D}_{2} \mathrm{O}$ and $0.01 \mathrm{mM}$ DSS. 


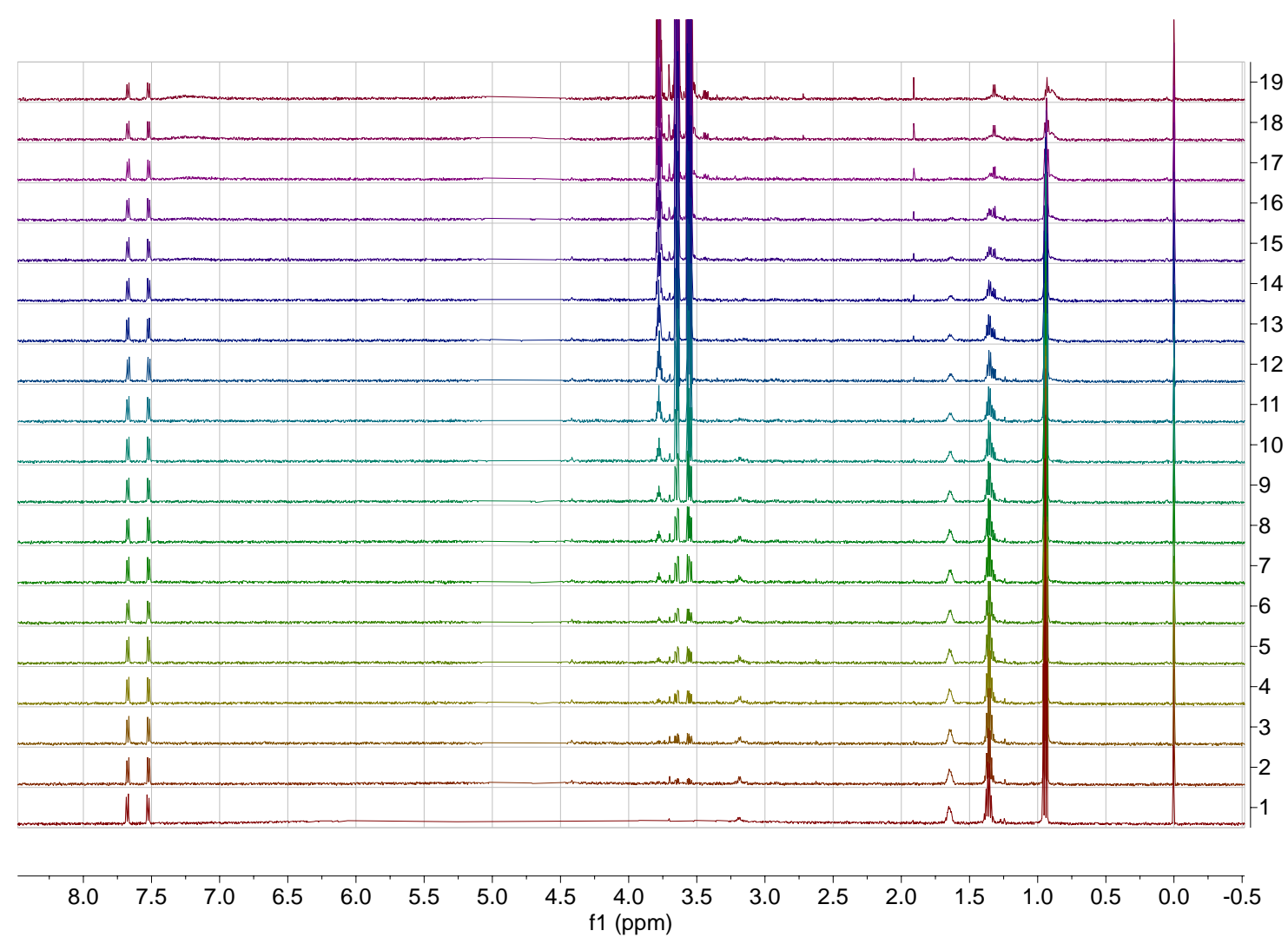

Figure S22 - Stack of 1D ${ }^{1} \mathrm{H}$ CPMG NMR spectrum of 3 at $0.1 \mathrm{mM}$ with increasing concentration of $E$. coli SMA nanodiscs (SMA nanodisc molar equivalents $=0$ (bottom), 0.002, 0.004, 0.006, 0.008, 0.01, 0.015, $0.021,0.032, .043,0.064,0.086,0.108,0.163,0.219,0.276,0.572,0.890,1.229$ (top)) in sodium phosphate buffer $\left(20 \mathrm{mM}\right.$ ) with $20 \mathrm{mM}$ sodium chloride at $\mathrm{pH} 7.4$, supplemented with $5 \% \mathrm{D}_{2} \mathrm{O}$ and $0.01 \mathrm{mM}$ DSS. 


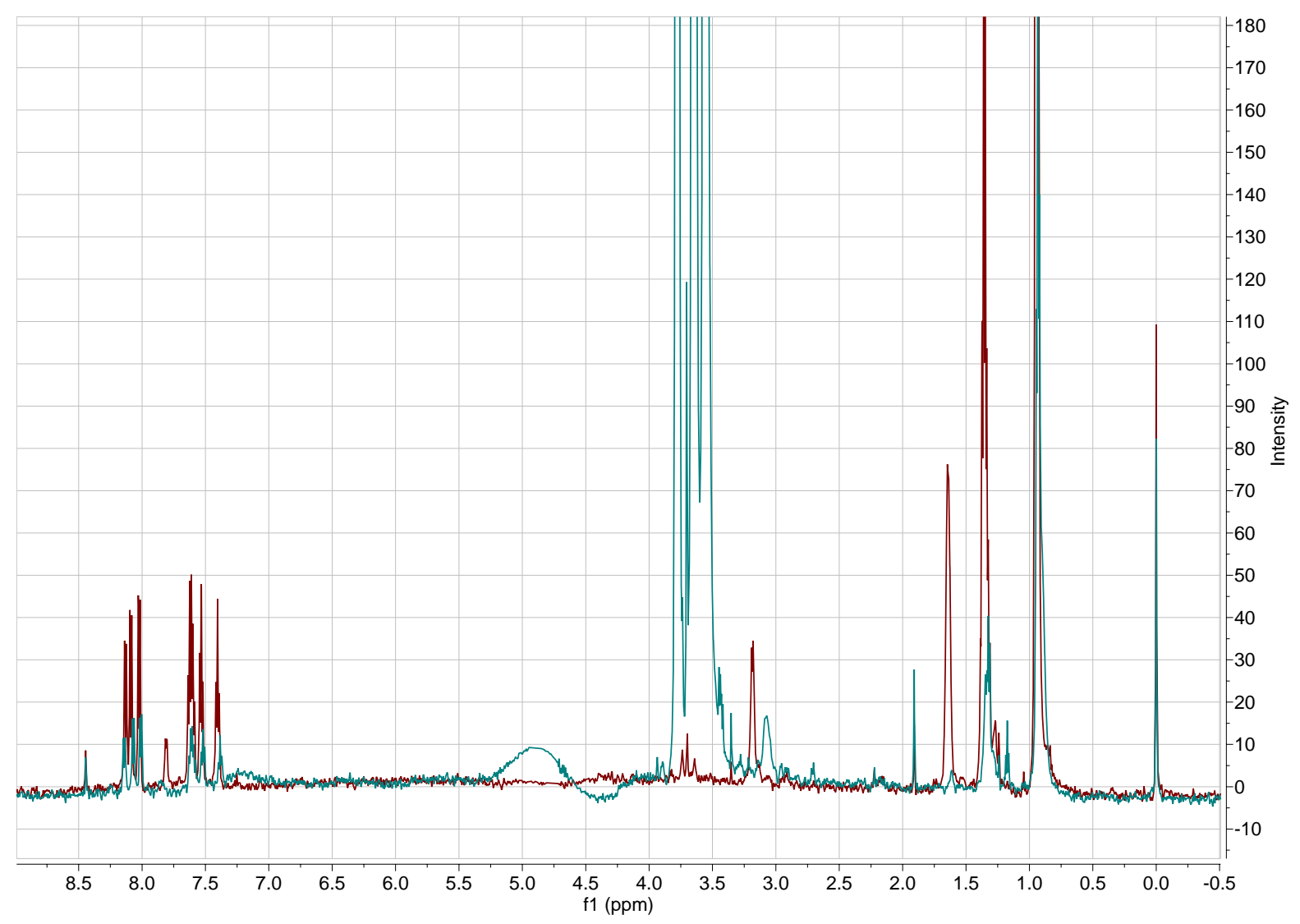

Figure S23 - Overlaid 1D ${ }^{1} \mathrm{H}$ CPMG NMR spectrum of $1(0.10 \mathrm{mM})$ only (red) and 1 in the presence of one molar equivalent DMPC SMA nanodiscs (green) in sodium phosphate buffer ( $20 \mathrm{mM}$ ) with $20 \mathrm{mM}$ sodium chloride at $\mathrm{pH} 7.4$, supplemented with $5 \% \mathrm{D}_{2} \mathrm{O}$ and $0.01 \mathrm{mM}$ DSS. 


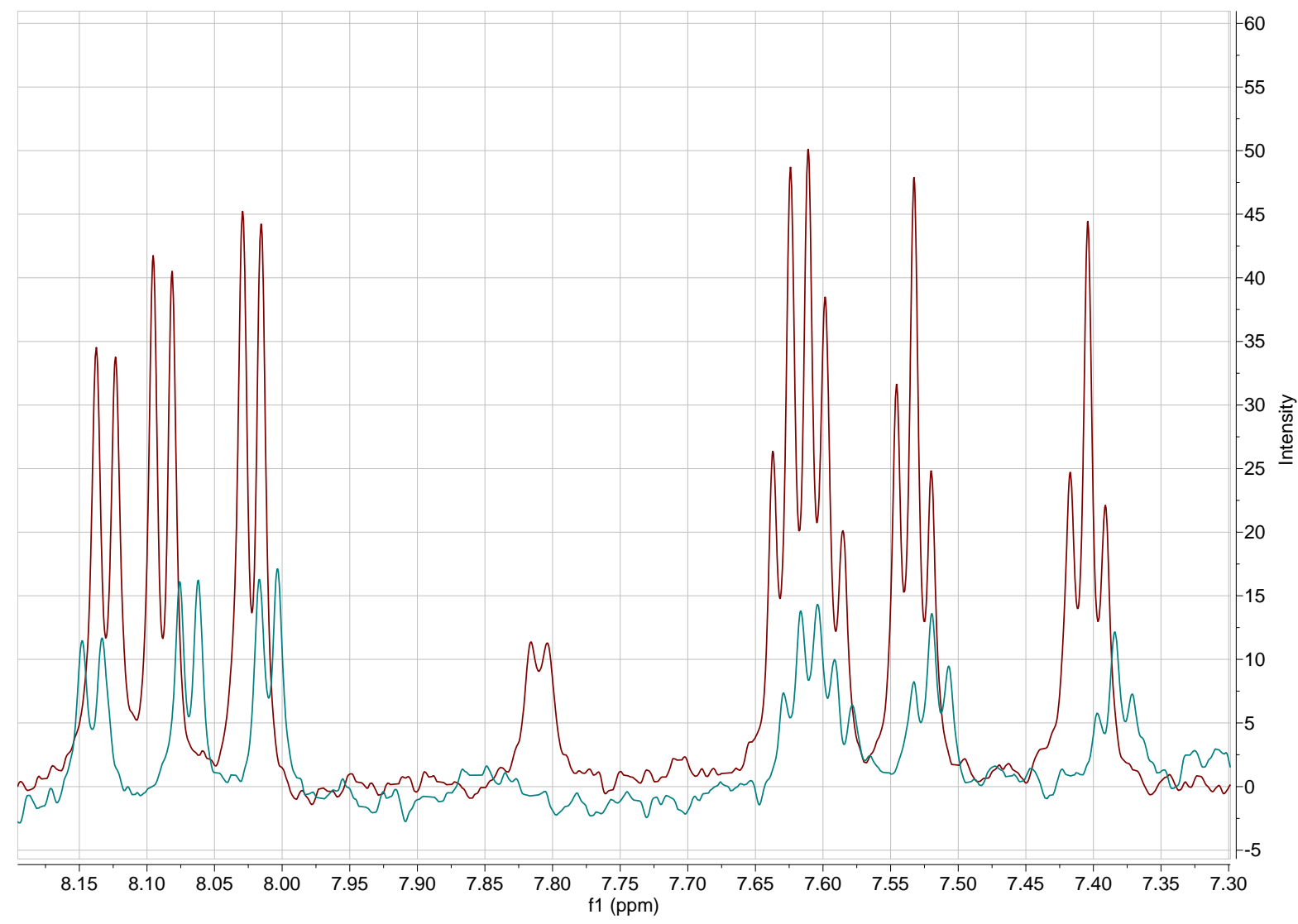

Figure S24 - Overlaid aromatic region of the 1D ${ }^{1} \mathrm{H}$ CPMG NMR spectrum of $1(0.10 \mathrm{mM})$ only (red) and 1 in the presence of one molar equivalent of DMPC SMA nanodiscs (green) in sodium phosphate buffer (20 $\mathrm{mM}$ ) with $20 \mathrm{mM}$ sodium chloride at $\mathrm{pH} 7.4$, supplemented with $5 \% \mathrm{D}_{2} \mathrm{O}$ and $0.01 \mathrm{mM}$ DSS. 


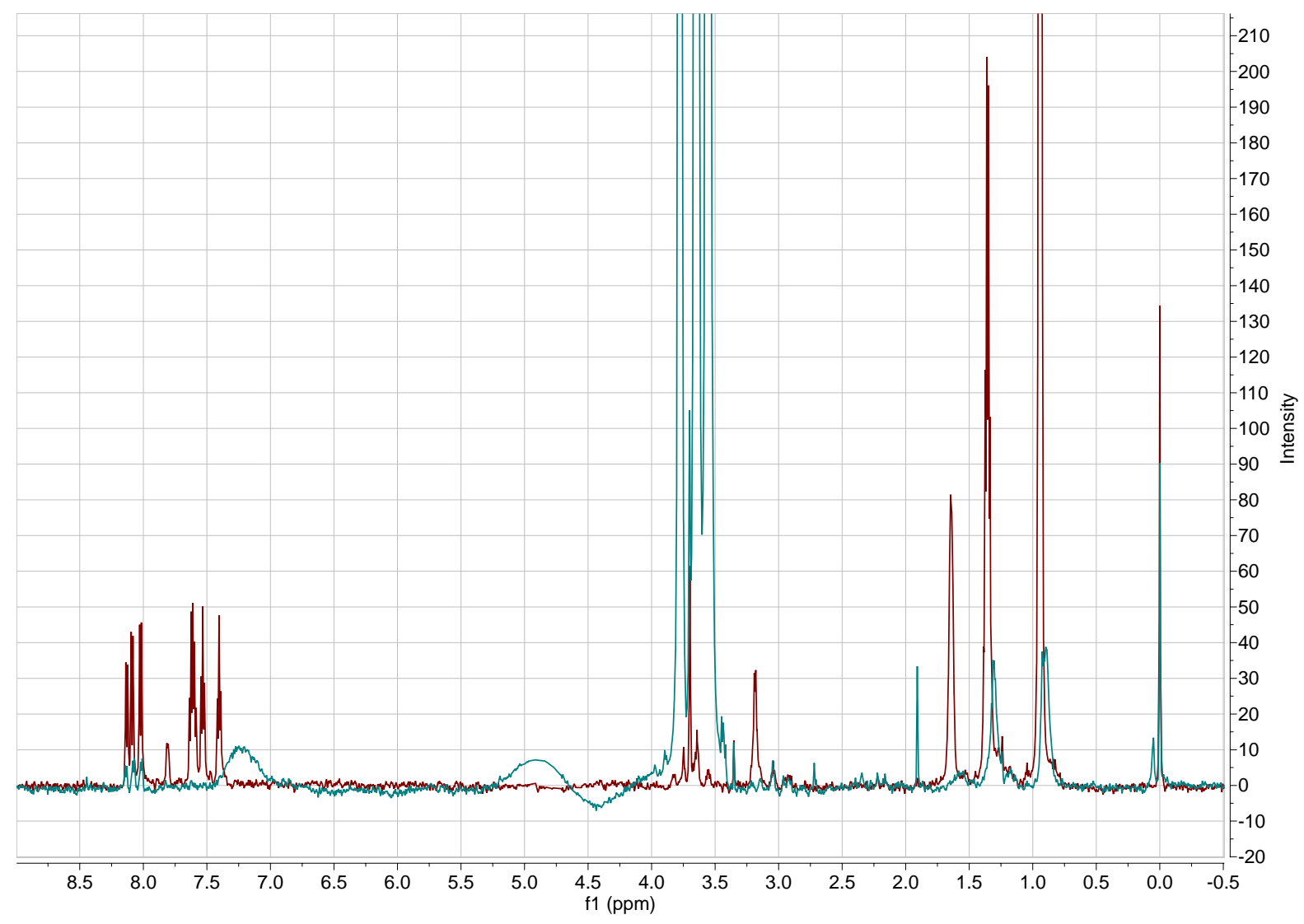

Figure S25 - Overlaid 1D ${ }^{1} \mathrm{H}$ CPMG NMR spectrum of 1 at $0.10 \mathrm{mM}$ only (red) and 1 in the presence of one molar equivalent $E$. coli SMA nanodiscs (green) in sodium phosphate buffer ( $20 \mathrm{mM}$ ) with $20 \mathrm{mM}$ sodium chloride at $\mathrm{pH} 7.4$, supplemented with $5 \% \mathrm{D}_{2} \mathrm{O}$ and $0.01 \mathrm{mM}$ DSS. 


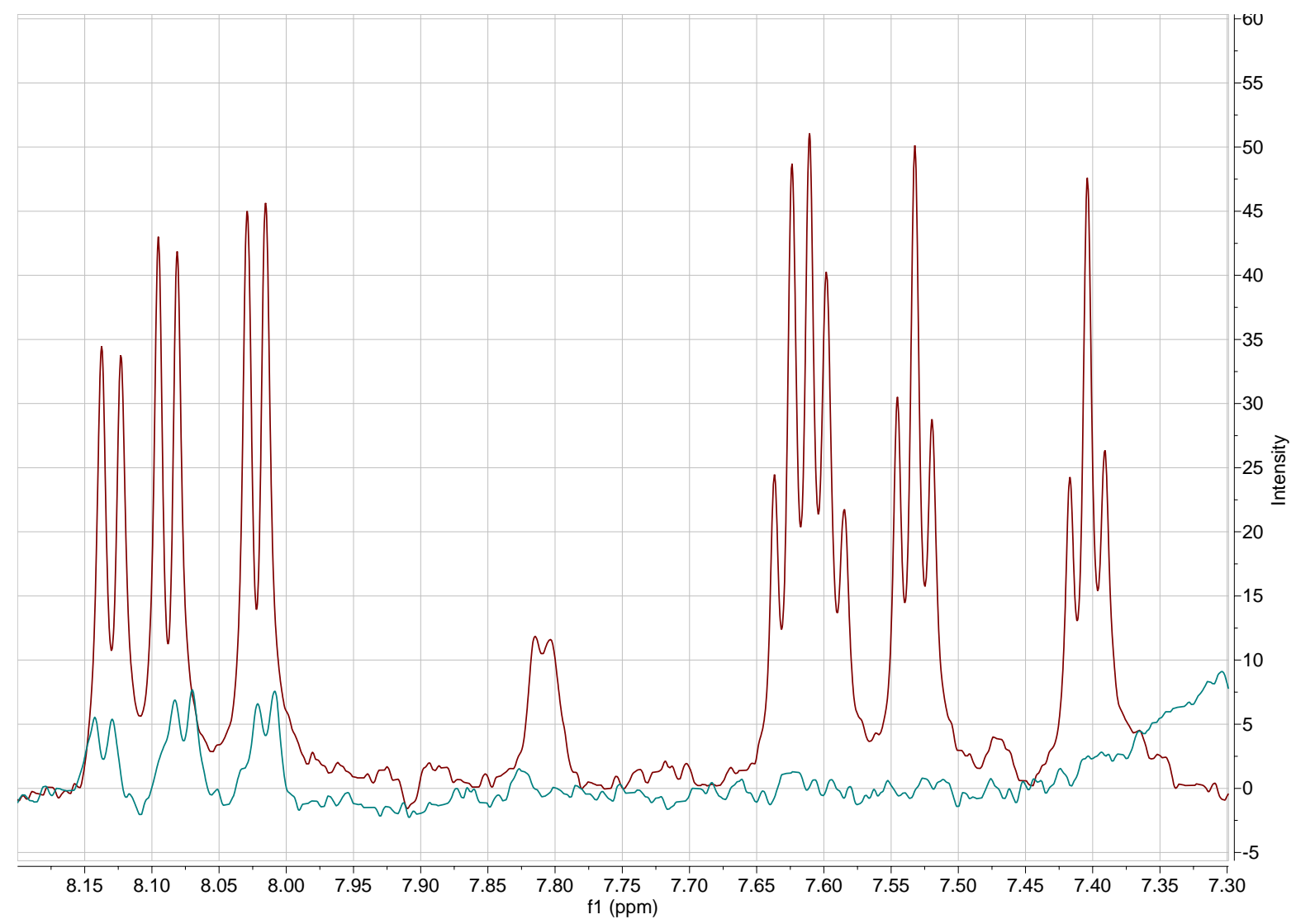

Figure S26 - Overlaid aromatic region of the $1 \mathrm{D}^{1} \mathrm{H}$ CPMG NMR spectrum of 1 at $0.10 \mathrm{mM}$ only (red) and 1 in the presence of one molar equivalent of $E$. coli SMA nanodiscs (green) in sodium phosphate buffer (20 mM) with $20 \mathrm{mM}$ sodium chloride at $\mathrm{pH} 7.4$, supplemented with $5 \% \mathrm{D}_{2} \mathrm{O}$ and $0.01 \mathrm{mM}$ DSS. 


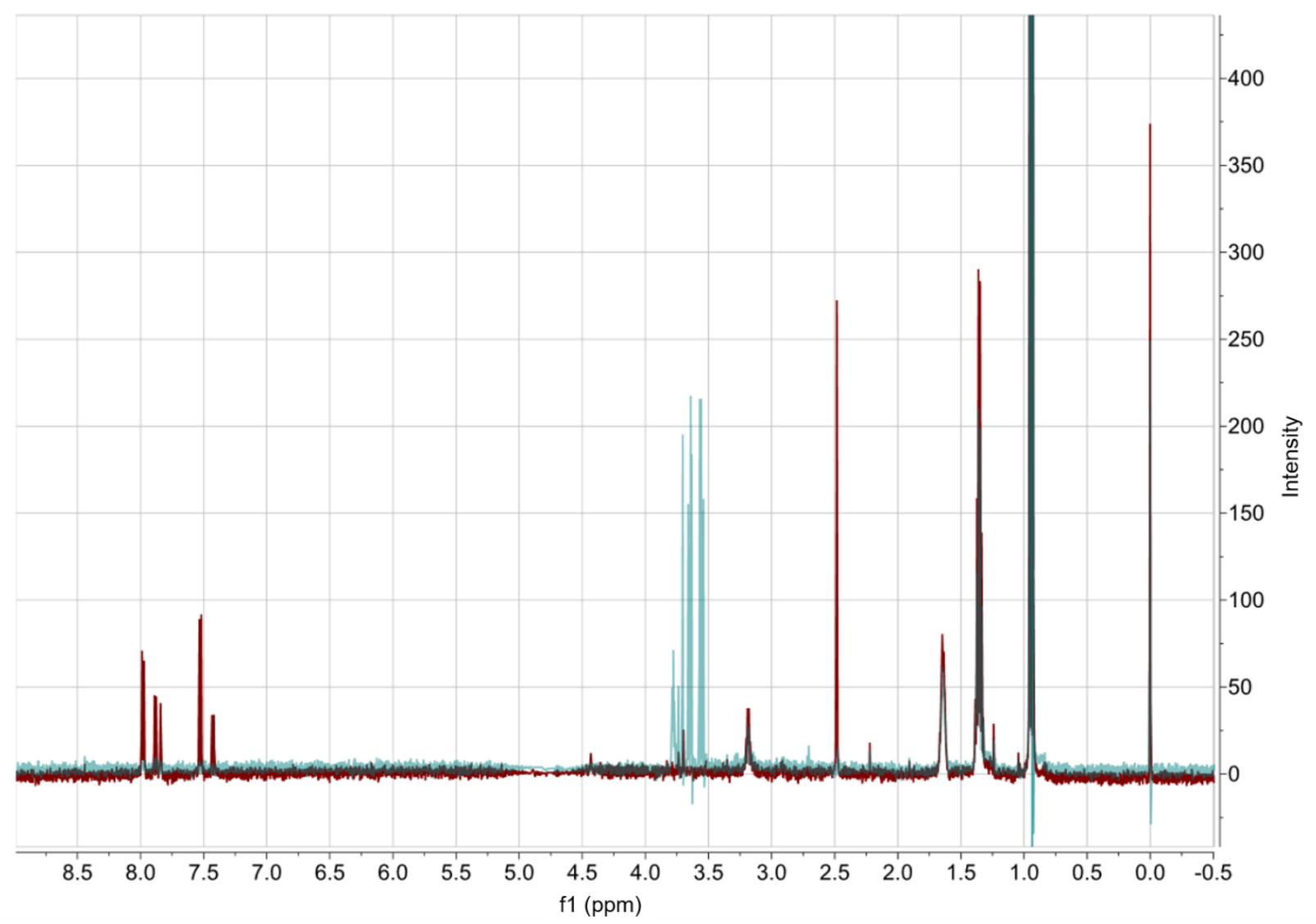

Figure S27 - Overlaid 1D ${ }^{1} \mathrm{H}$ CPMG NMR spectrum of $\mathbf{2}$ at $0.10 \mathrm{mM}$ only (red) and $\mathbf{2}$ in the presence of 0.031 molar equivalents of DMPC SMA nanodiscs (green) in sodium phosphate buffer $(20 \mathrm{mM})$ with 20 $\mathrm{mM}$ sodium chloride at $\mathrm{pH} 7.4$, supplemented with $5 \% \mathrm{D}_{2} \mathrm{O}$ and $0.01 \mathrm{mM}$ DSS. 


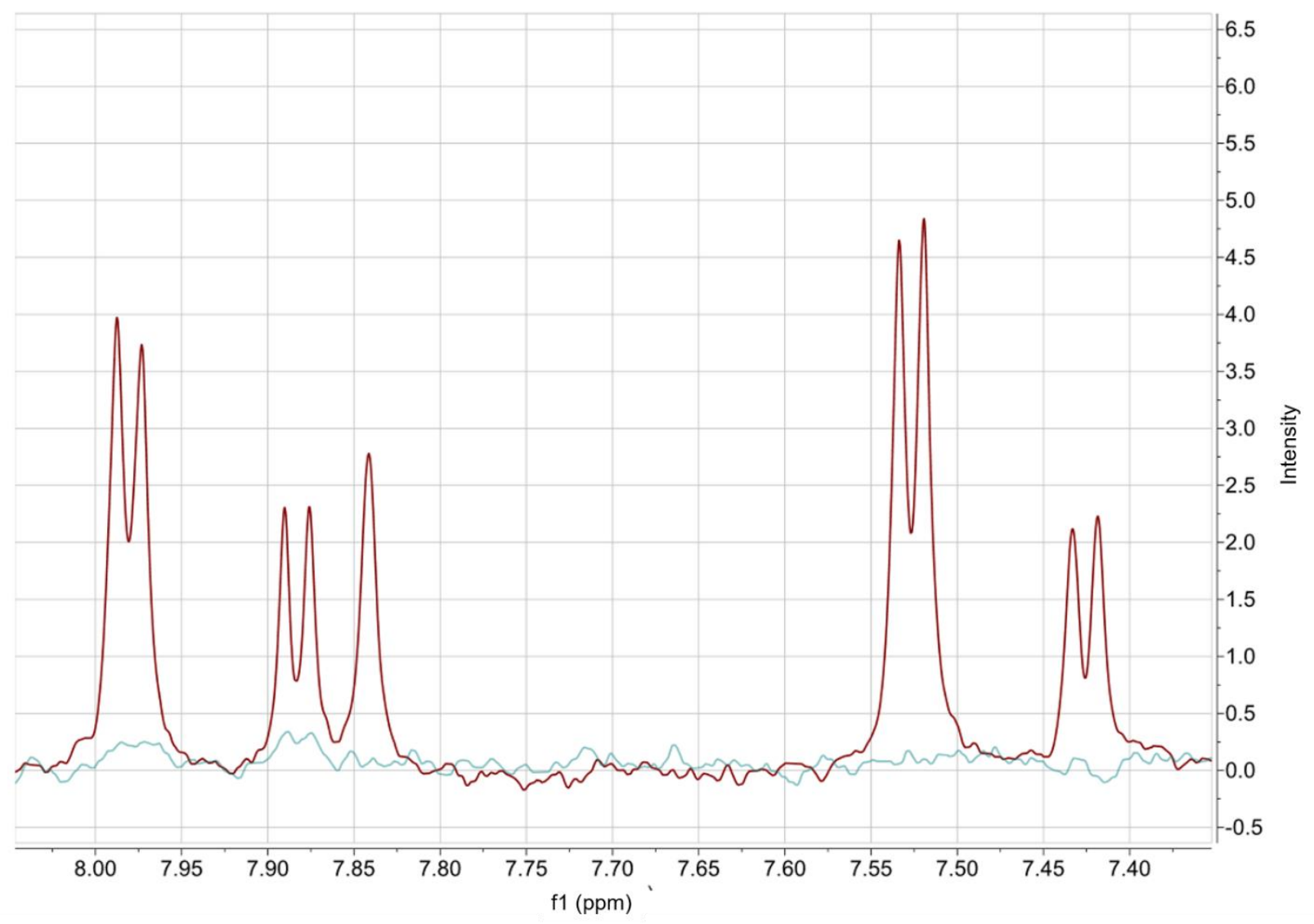

Figure S28 - Overlaid aromatic region of the $1 \mathrm{D}{ }^{1} \mathrm{H}$ CPMG NMR spectrum of 2 at $0.10 \mathrm{mM}$ only (red) and 2 in the presence of 0.031 molar equivalents of DMPC SMA nanodiscs (green) in sodium phosphate buffer (20 mM) with $20 \mathrm{mM}$ sodium chloride at $\mathrm{pH} 7.4$, supplemented with $5 \% \mathrm{D}_{2} \mathrm{O}$ and $0.01 \mathrm{mM}$ DSS. 


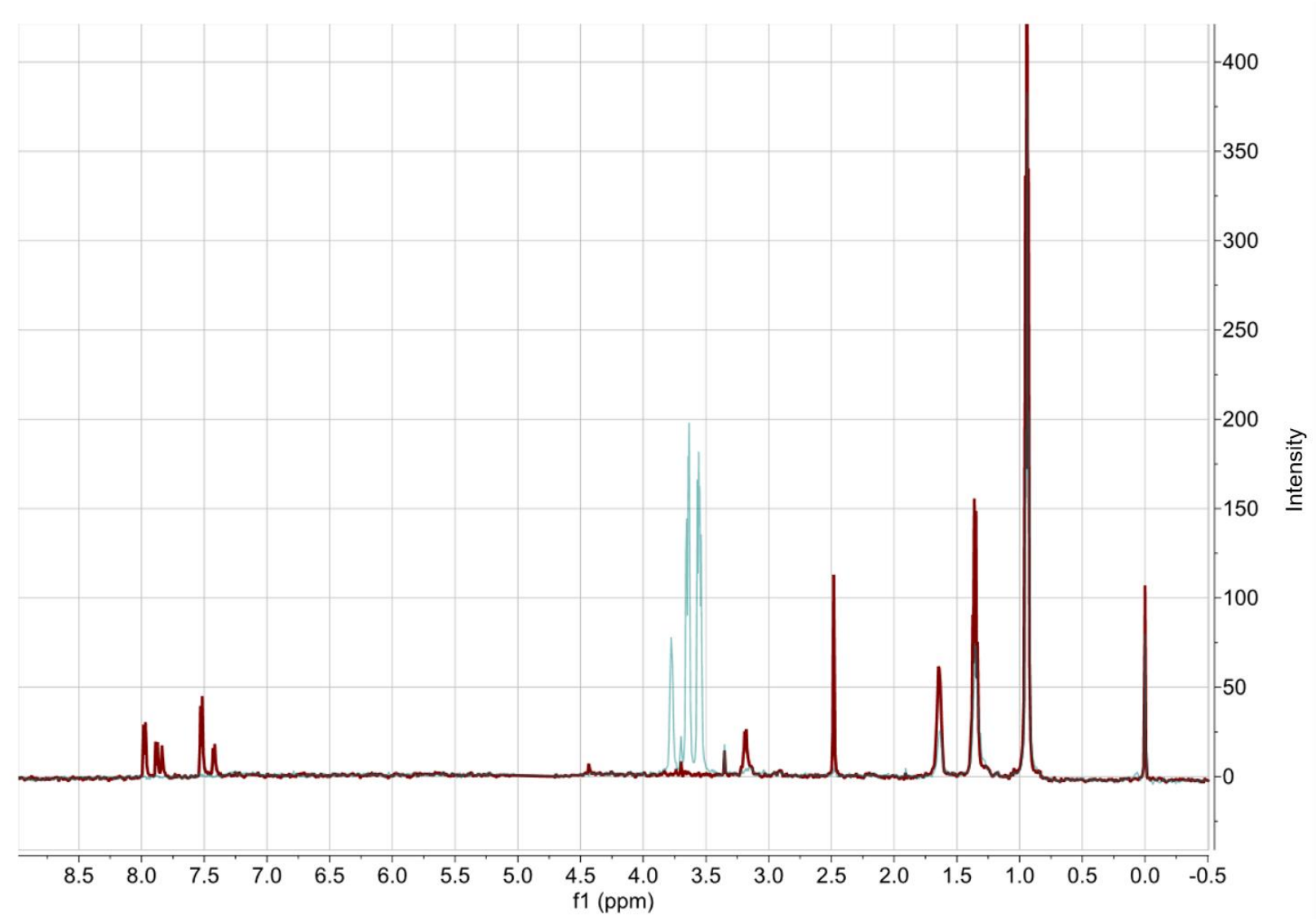

Figure S29 - Overlaid 1D ${ }^{1} \mathrm{H}$ CPMG NMR spectrum of $\mathbf{2}$ at $0.10 \mathrm{mM}$ only (red) and $\mathbf{2}$ in the presence of 0.031 molar equivalents of $E$. coli SMA nanodiscs (green) in sodium phosphate buffer $(20 \mathrm{mM})$ with 20 $\mathrm{mM}$ sodium chloride at $\mathrm{pH} 7.4$, supplemented with $5 \% \mathrm{D}_{2} \mathrm{O}$ and $0.01 \mathrm{mM}$ DSS. 


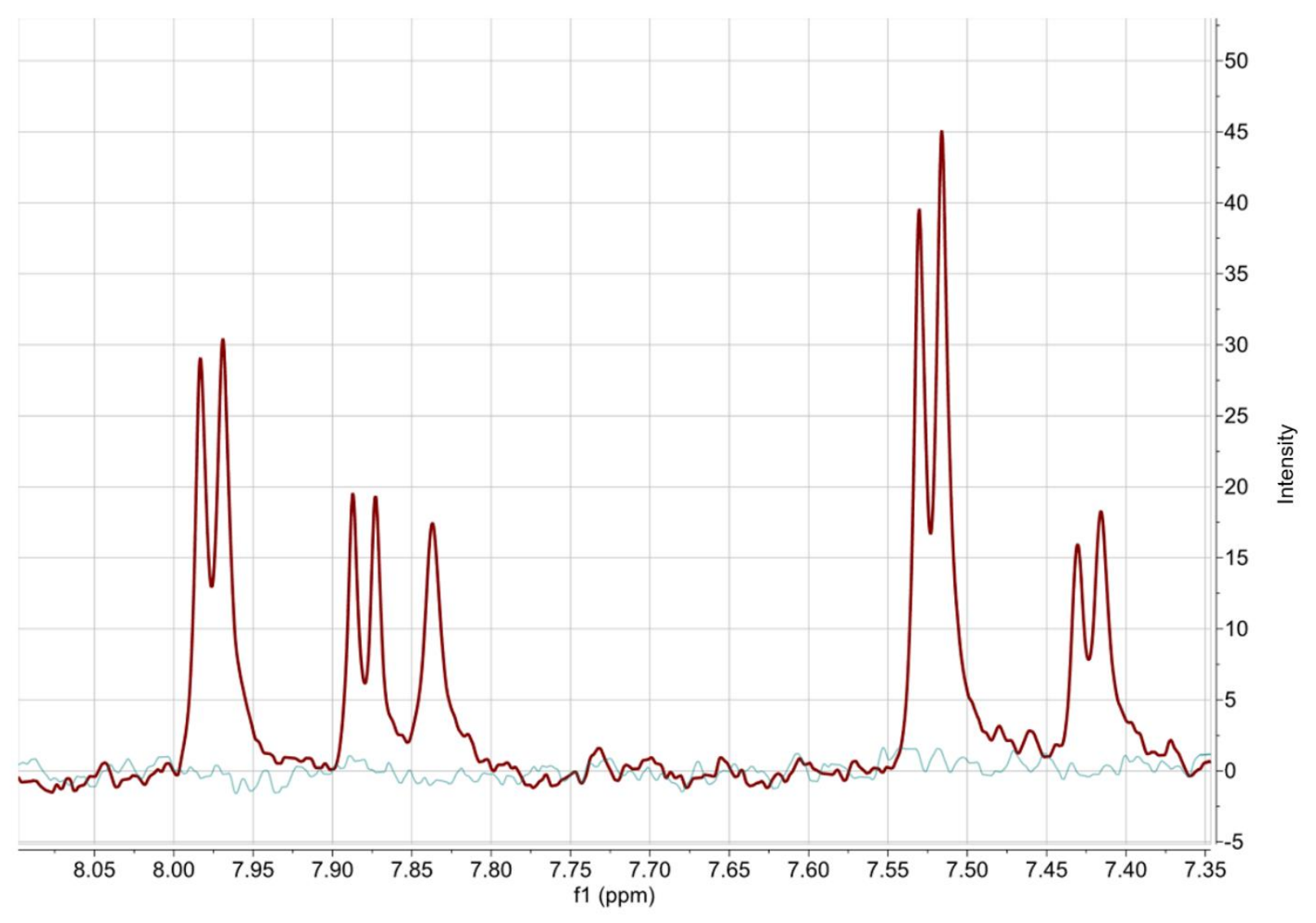

Figure S30 - Overlaid aromatic region of the $1 \mathrm{D}{ }^{1} \mathrm{H}$ CPMG NMR spectrum of 2 at $0.10 \mathrm{mM}$ only (red) and 2 in the presence of 0.031 molar equivalents of $E$. coli SMA nanodiscs (green) in sodium phosphate buffer (20 mM) with $20 \mathrm{mM}$ sodium chloride at $\mathrm{pH} 7.4$, supplemented with $5 \% \mathrm{D}_{2} \mathrm{O}$ and $0.01 \mathrm{mM}$ DSS. 


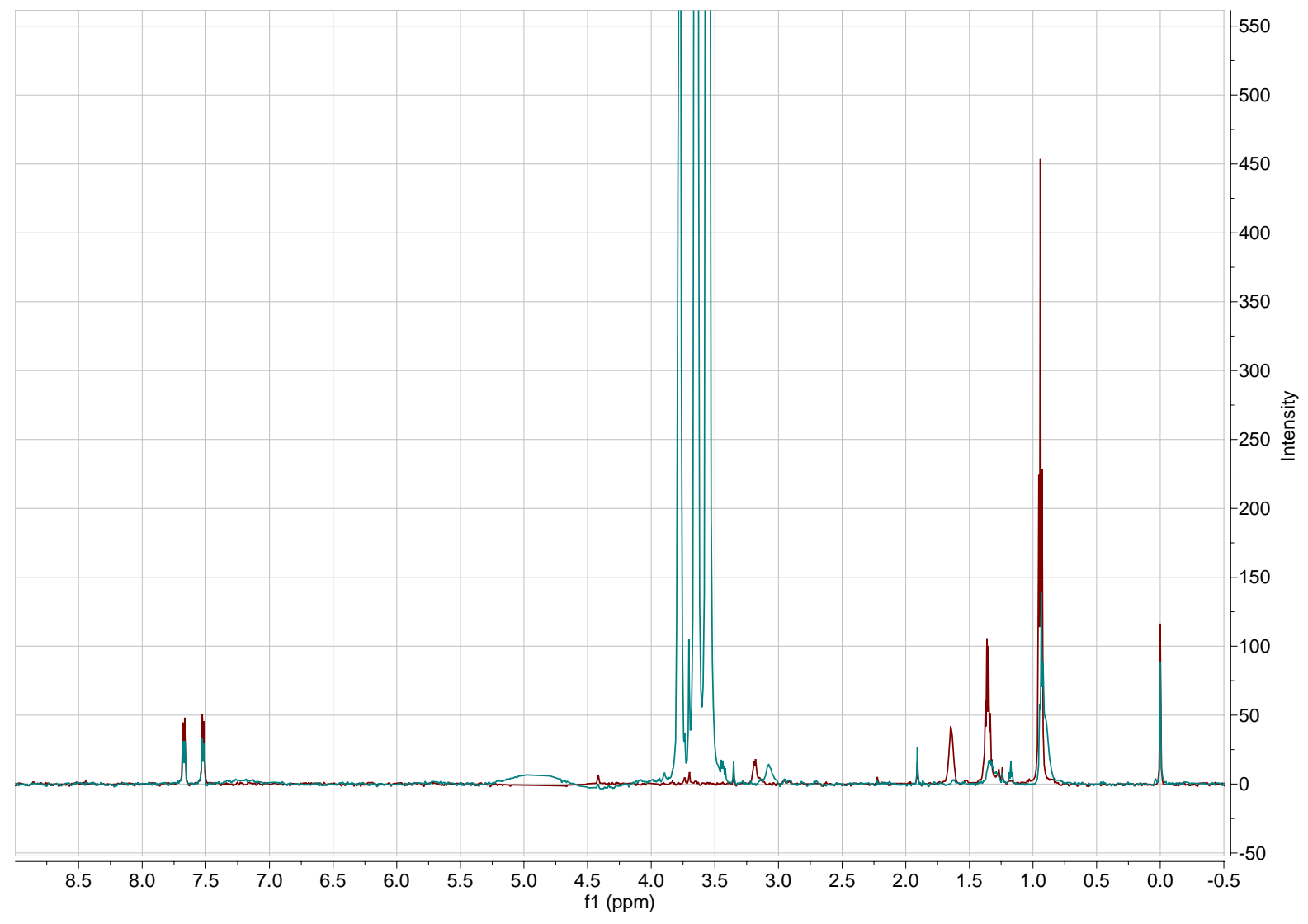

Figure S31 - Overlaid 1D ${ }^{1} \mathrm{H}$ CPMG NMR spectrum of 3 at $0.10 \mathrm{mM}$ only (red) and 3 in the presence of 1.2 molar equivalents of DMPC SMA nanodiscs (green) in sodium phosphate buffer (20 mM) with $20 \mathrm{mM}$ sodium chloride at $\mathrm{pH} 7.4$, supplemented with $5 \% \mathrm{D}_{2} \mathrm{O}$ and $0.01 \mathrm{mM}$ DSS. 


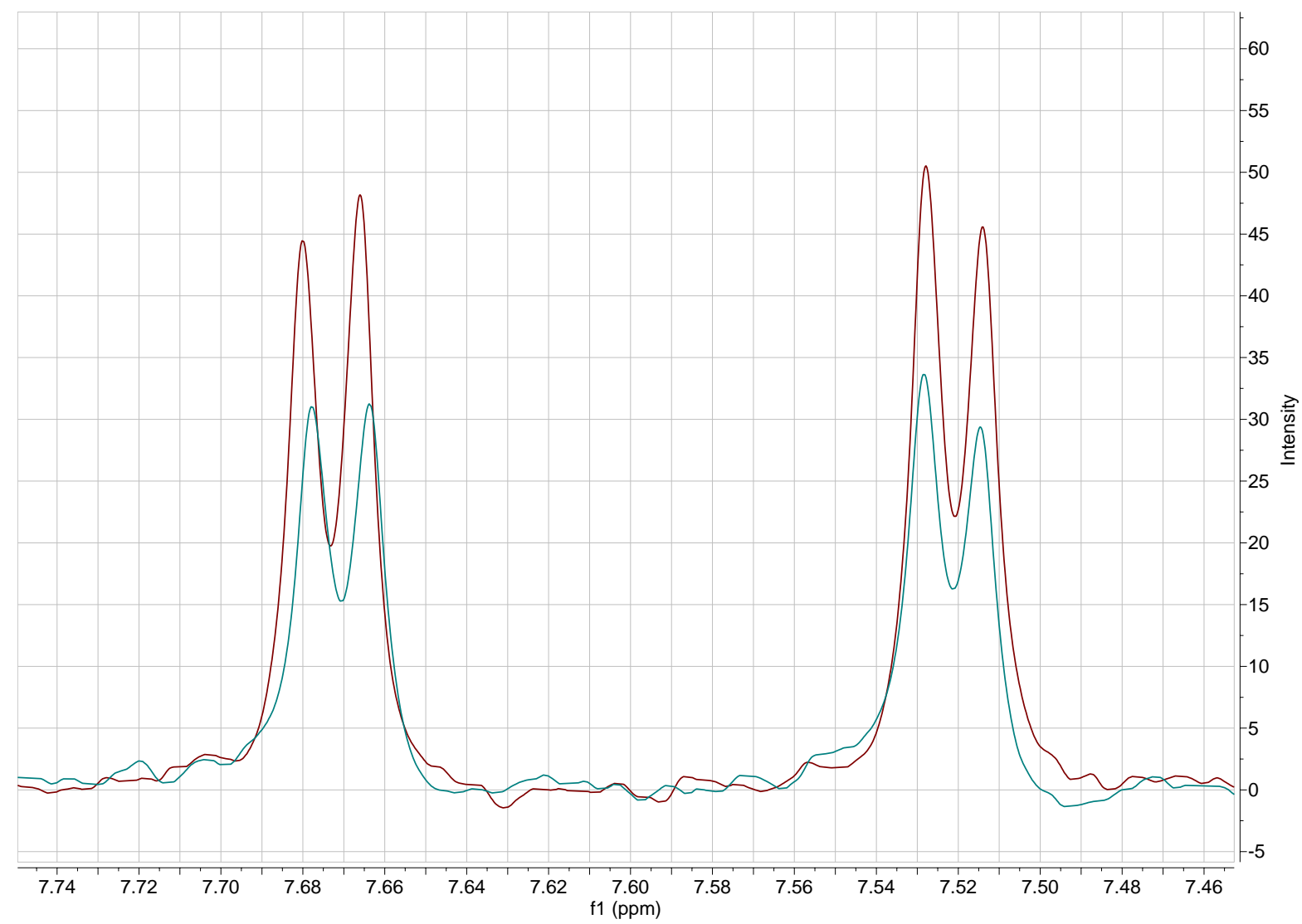

Figure S32 - Overlaid aromatic region of the $1 \mathrm{D}^{1} \mathrm{H}$ CPMG NMR spectrum of 3 at $0.10 \mathrm{mM}$ free (red) and 3 in the presence of 1.2 molar equivalent of DMPC SMA nanodiscs (green) in sodium phosphate buffer (20 $\mathrm{mM}$ ) with $20 \mathrm{mM}$ sodium chloride at $\mathrm{pH} 7.4$, supplemented with $5 \% \mathrm{D}_{2} \mathrm{O}$ and $0.01 \mathrm{mM}$ DSS. 


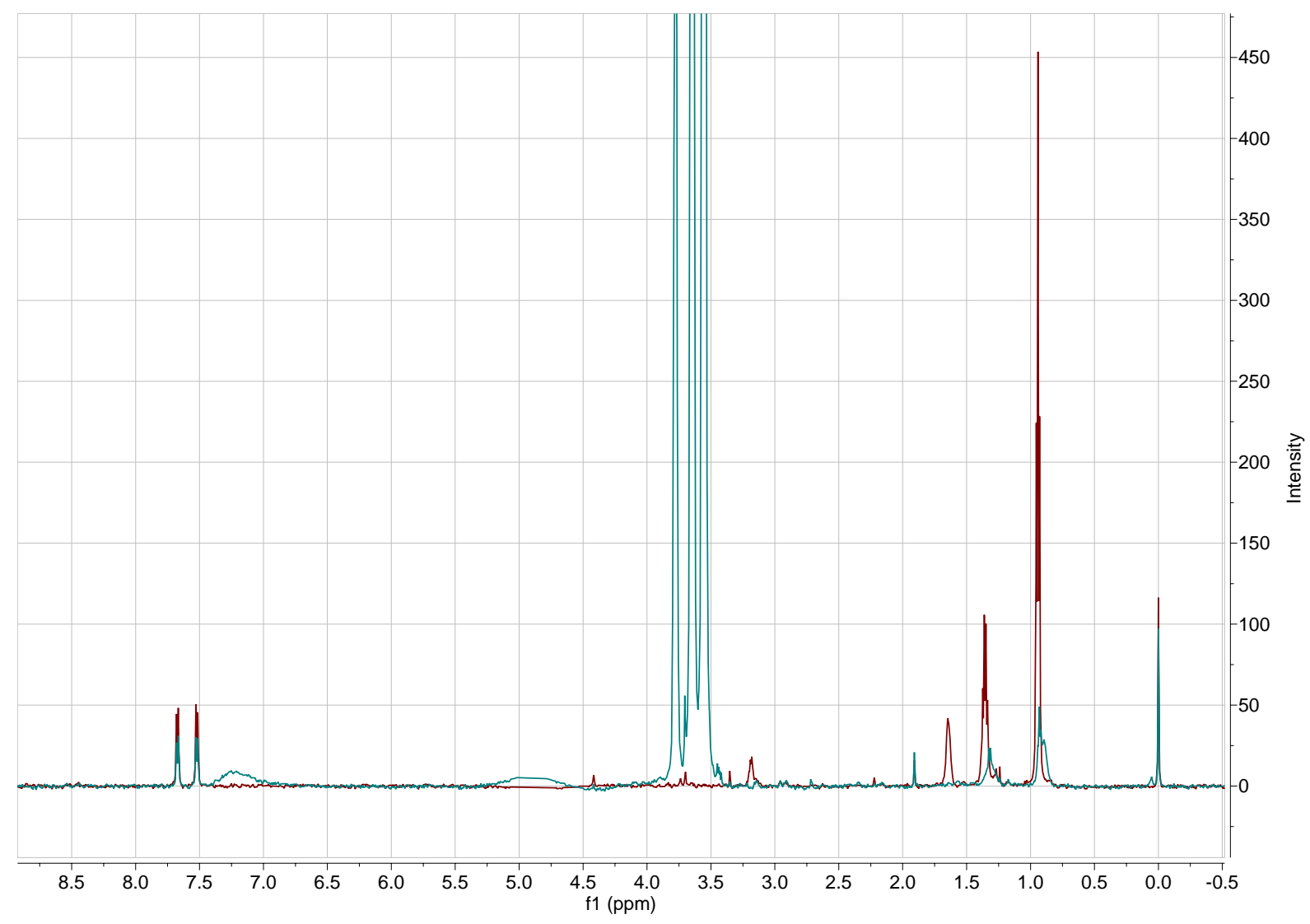

Figure S33 - Overlaid 1D ${ }^{1} \mathrm{H}$ CPMG NMR spectrum of 3 at $0.10 \mathrm{mM}$ only (red) and 3 in the presence of 1.2 molar equivalents of $E$. coli SMA nanodiscs (green) in sodium phosphate buffer ( $20 \mathrm{mM})$ with $20 \mathrm{mM}$ sodium chloride at $\mathrm{pH} 7.4$, supplemented with $5 \% \mathrm{D}_{2} \mathrm{O}$ and $0.01 \mathrm{mM}$ DSS. 


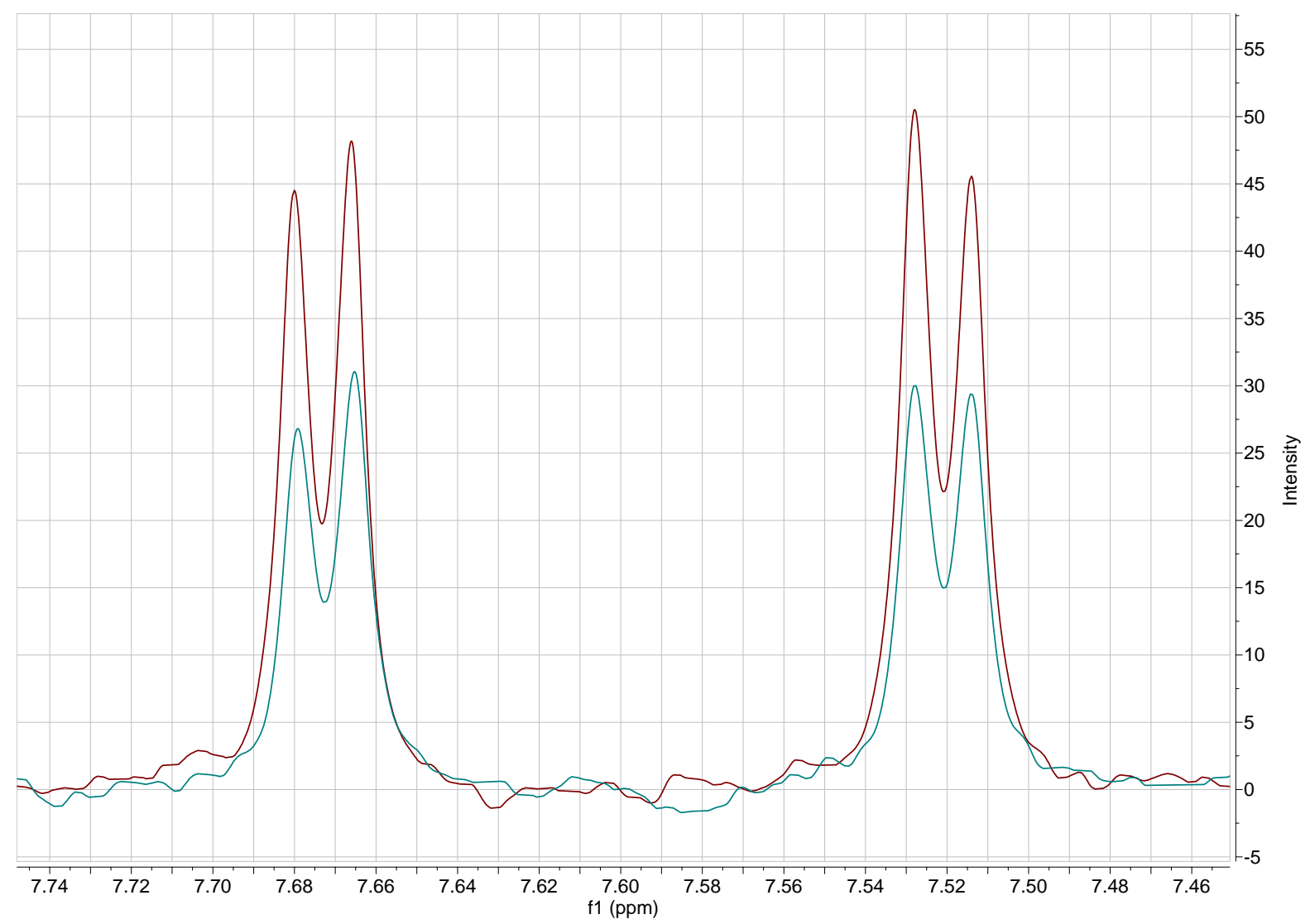

Figure S34 - Overlaid aromatic region of the $1 \mathrm{D}^{1} \mathrm{H}$ CPMG NMR spectrum of 3 at $0.10 \mathrm{mM}$ only (red) and 3 in the presence of 1.2 molar equivalents of $E$. coli SMA nanodiscs (green) in sodium phosphate buffer (20 mM) with $20 \mathrm{mM}$ sodium chloride at $\mathrm{pH} 7.4$, supplemented with $5 \% \mathrm{D}_{2} \mathrm{O}$ and $0.01 \mathrm{mM}$ DSS. 


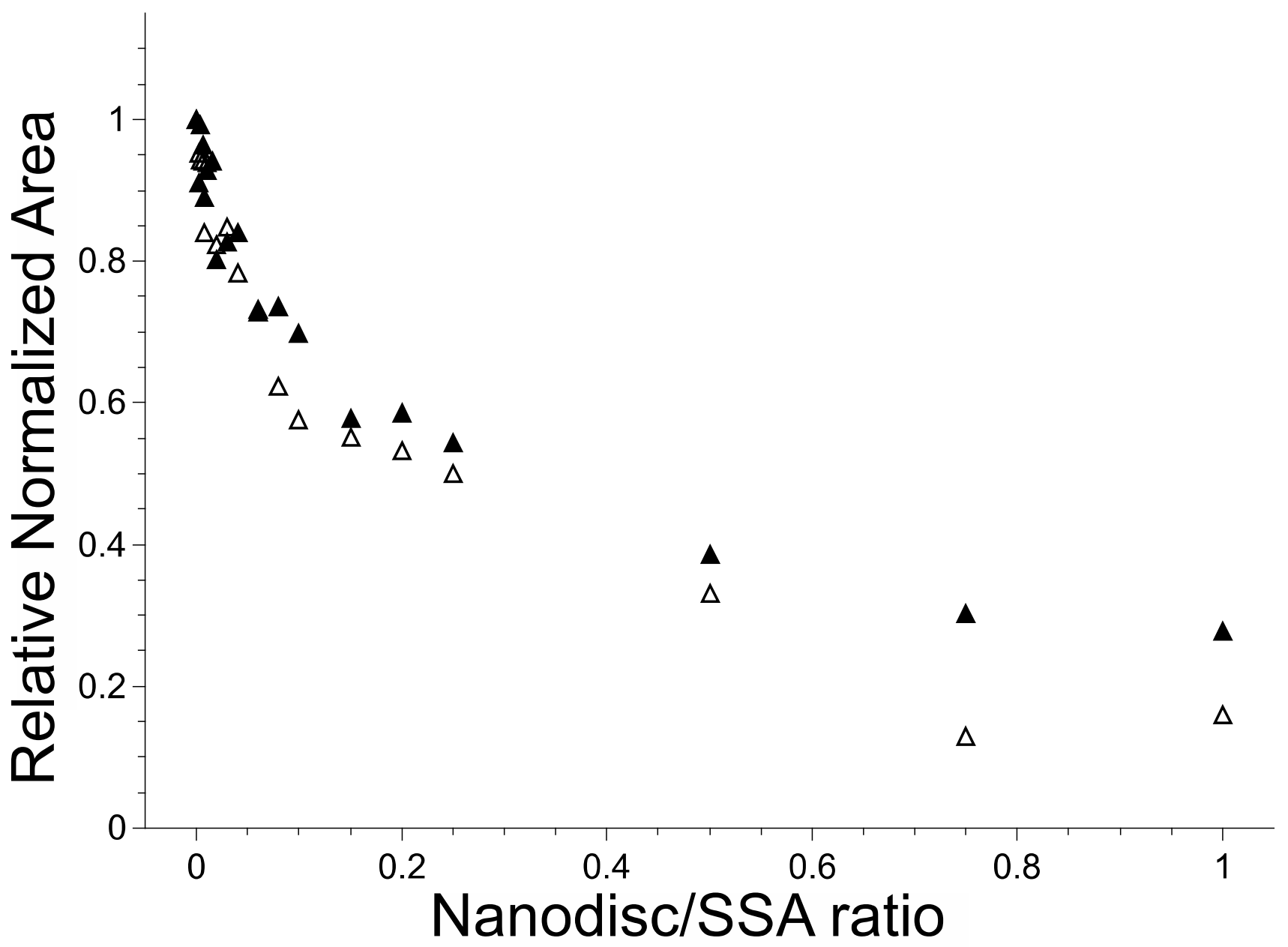

Figure S35 - The relative normalized area of the most downfield aromatic SSA resonance of 1 with E. coli lipid (open symbols) and DMPC (filled symbols) nanodiscs. 


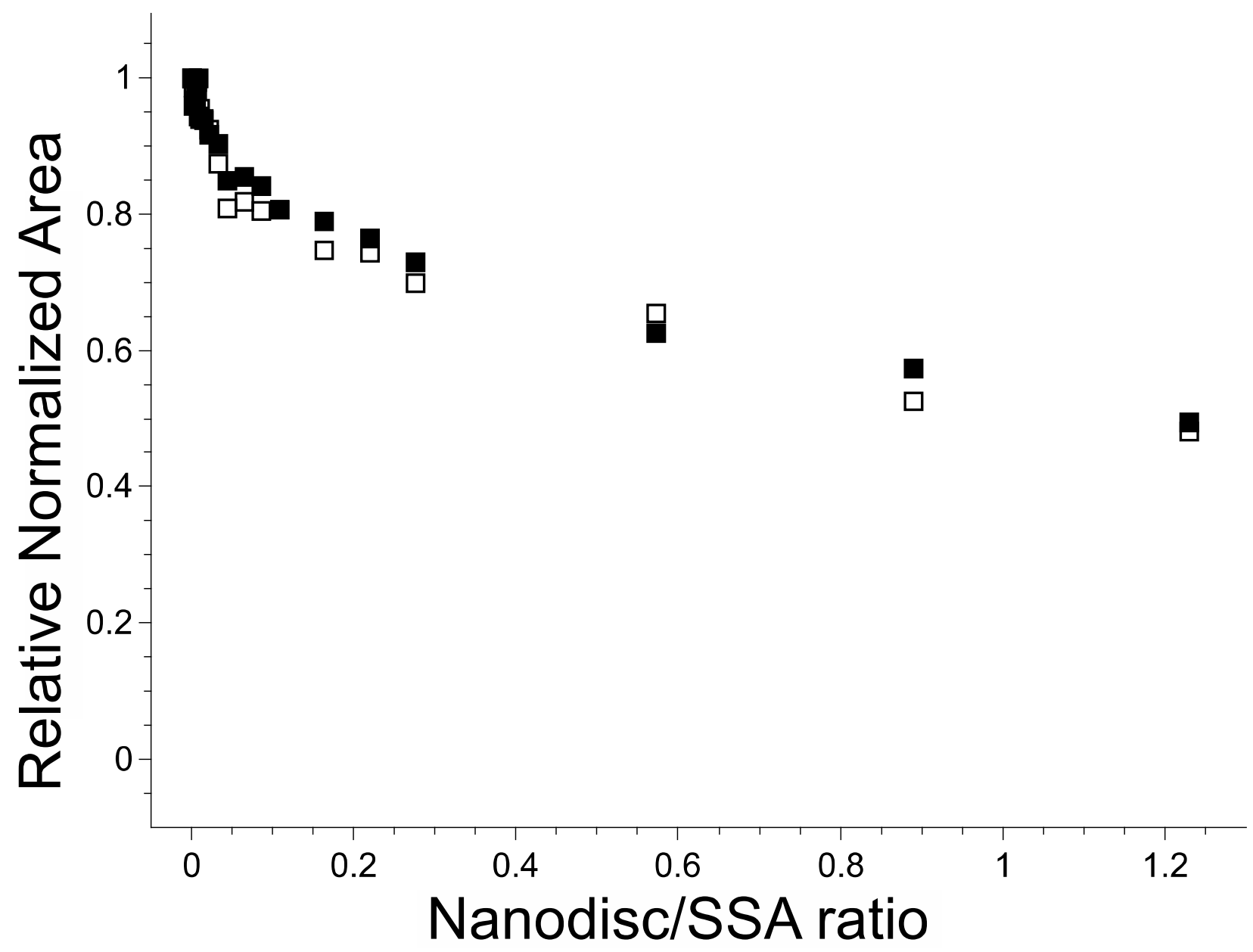

Figure S36 - The relative normalized area of the most downfield aromatic SSA resonance of $\mathbf{3}$ with E. coli lipid (open symbols) and DMPC (filled symbols) nanodiscs. 


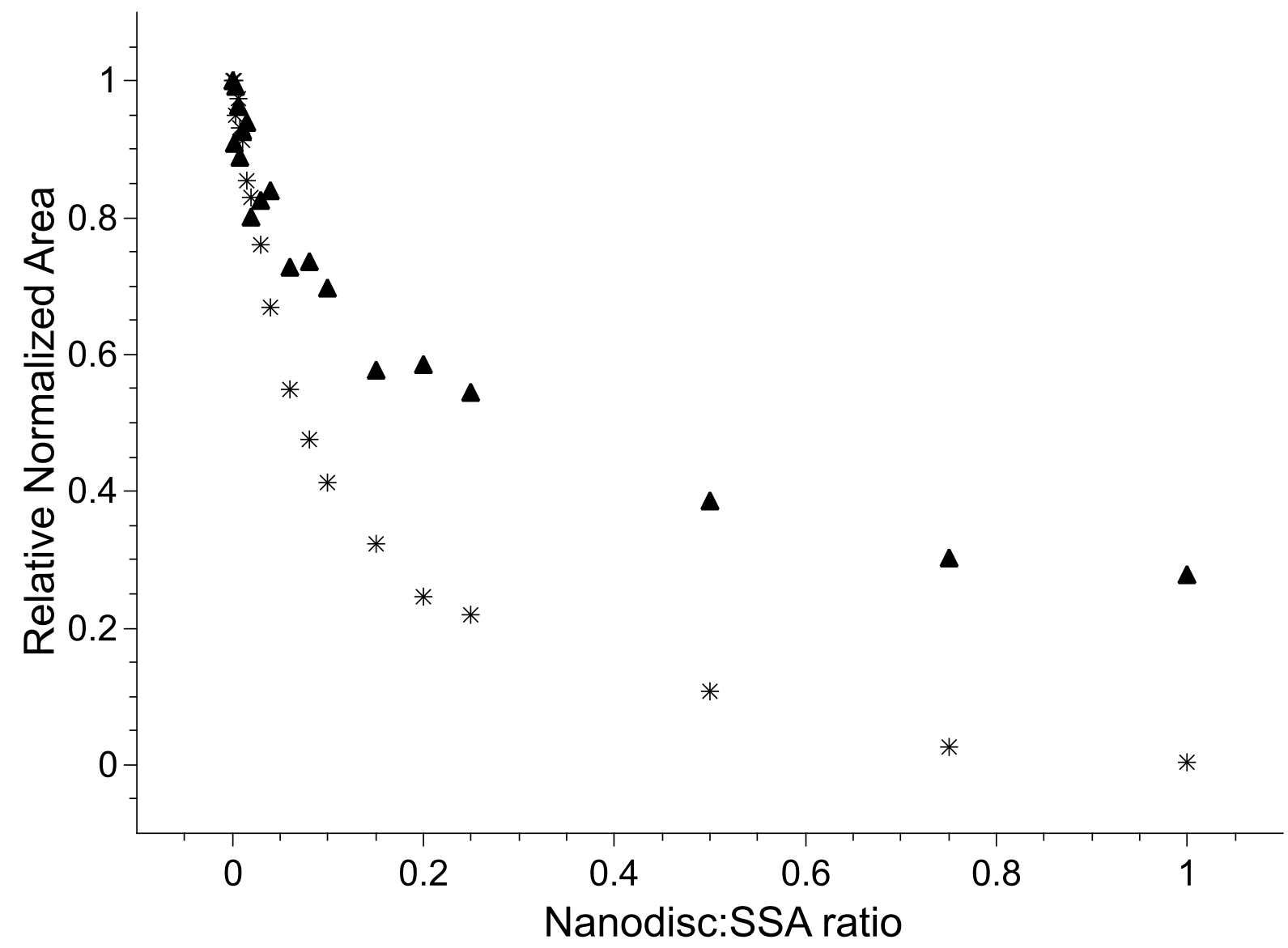

Figure S37 - The relative normalized area of the most downfield aromatic SSA resonance of 1 (filled triangles) and its associated TBA cation (stars) upon titration with DMPC nanodiscs. 


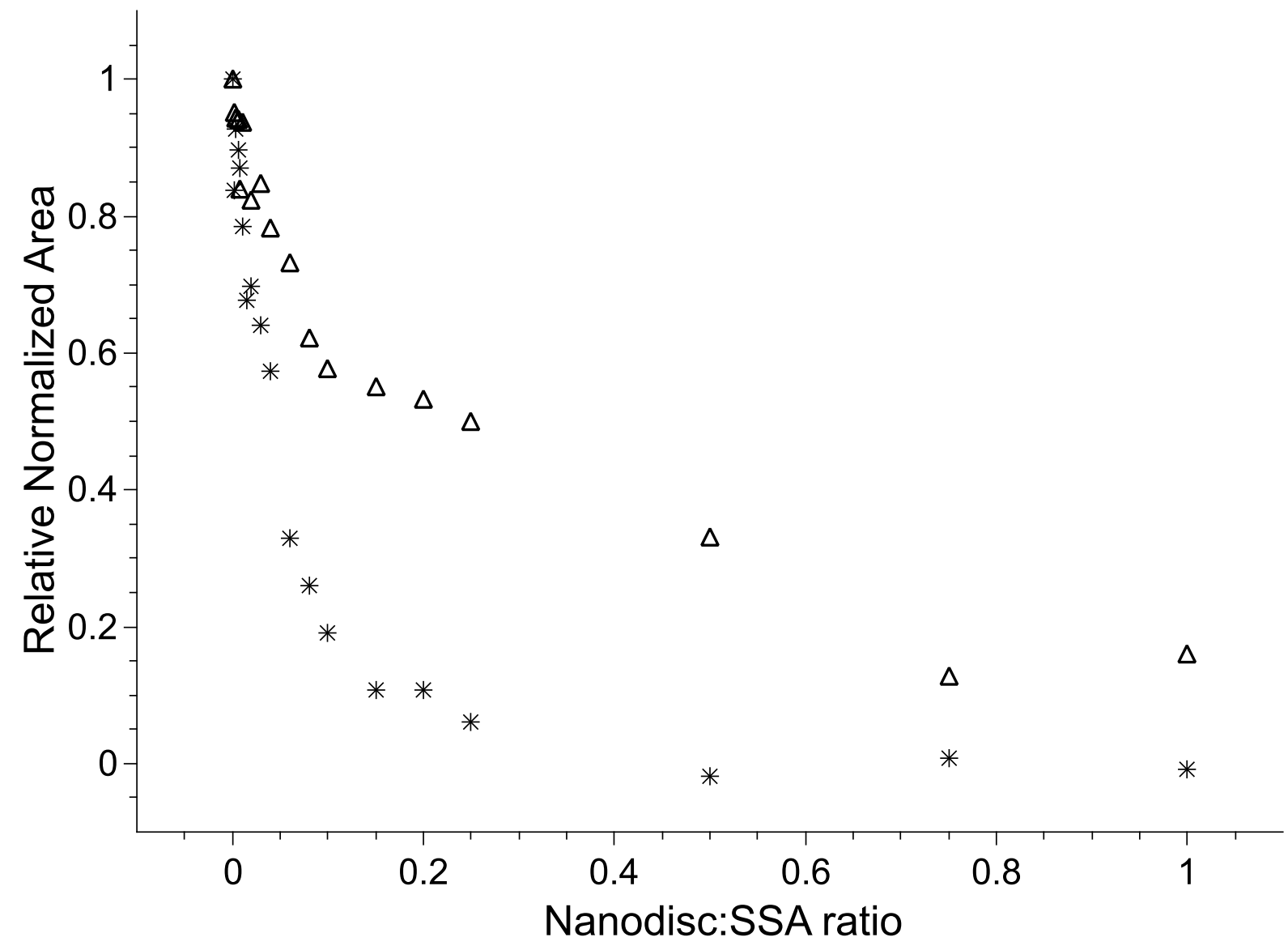

Figure S38 - The relative normalized area of the most downfield aromatic SSA resonance of 1 (open triangles) and its associated TBA cation (stars) upon titration with E. coli nanodiscs. 


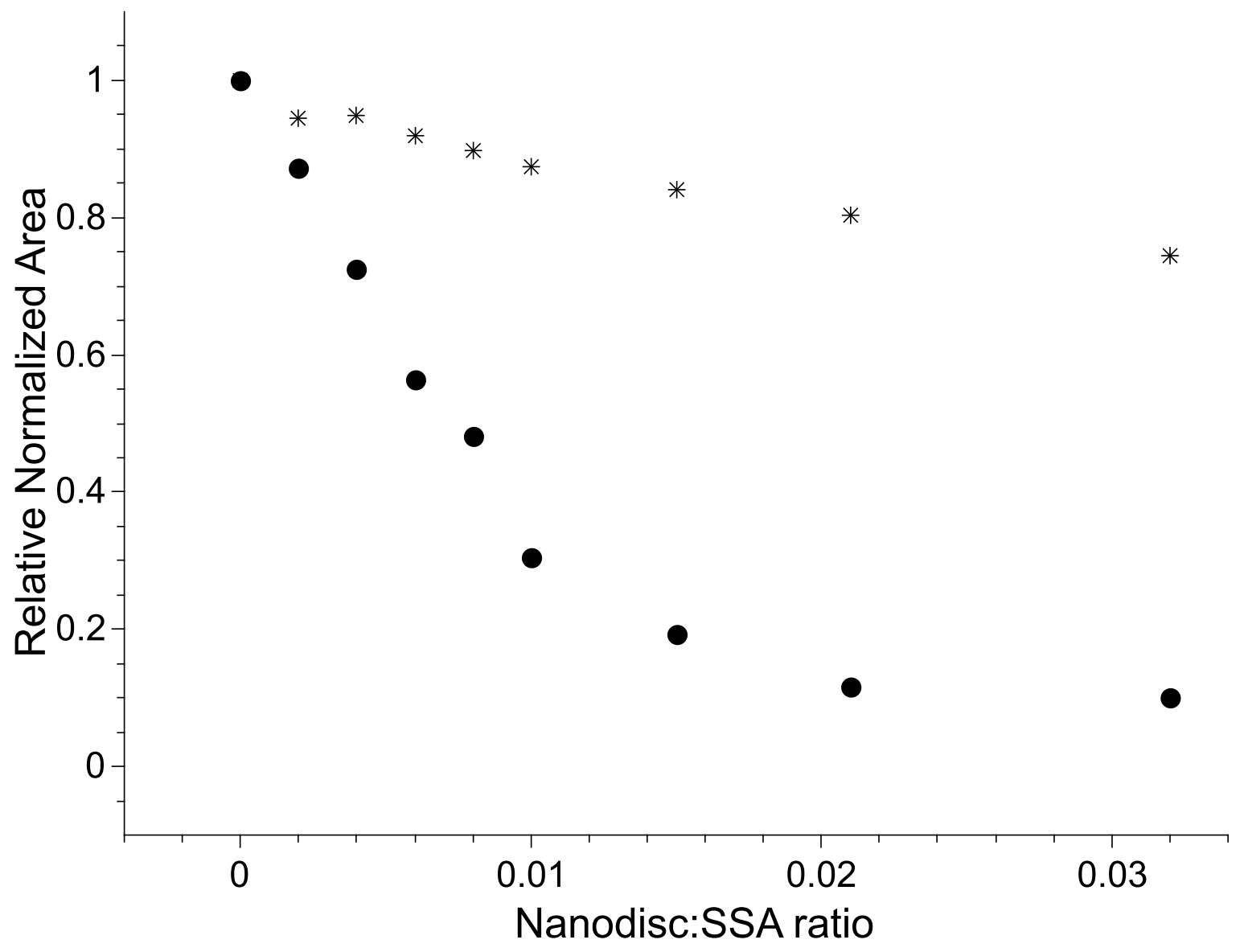

Figure S39 - The relative normalized area of the most downfield aromatic SSA resonance of $\mathbf{2}$ (filled circles) and its associated TBA cation (stars) upon titration with DMPC nanodiscs. 


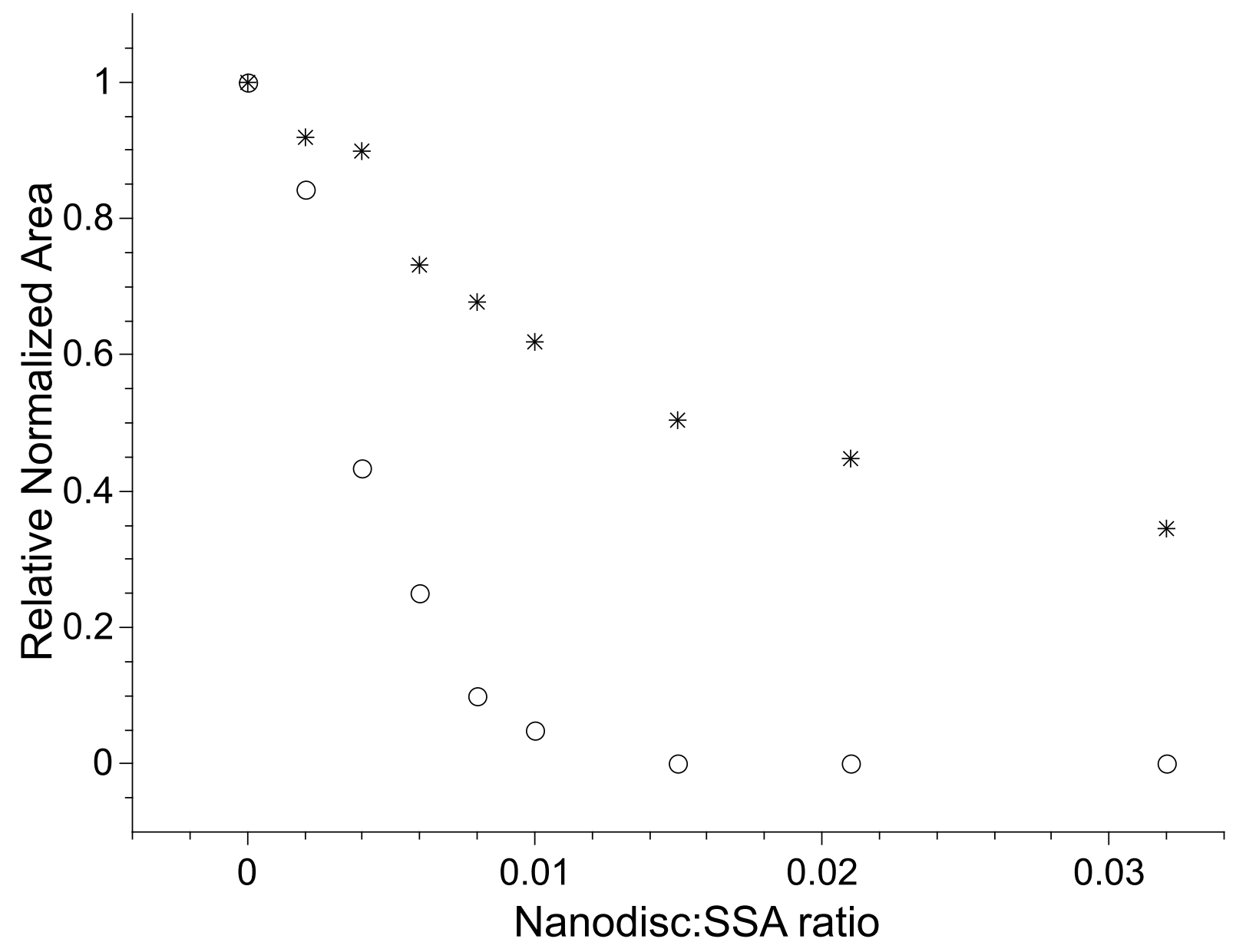

Figure S40 - The relative normalized area of the most downfield aromatic SSA resonance of $\mathbf{2}$ (open circles) and its associated TBA cation (stars) upon titration with E. coli nanodiscs. 


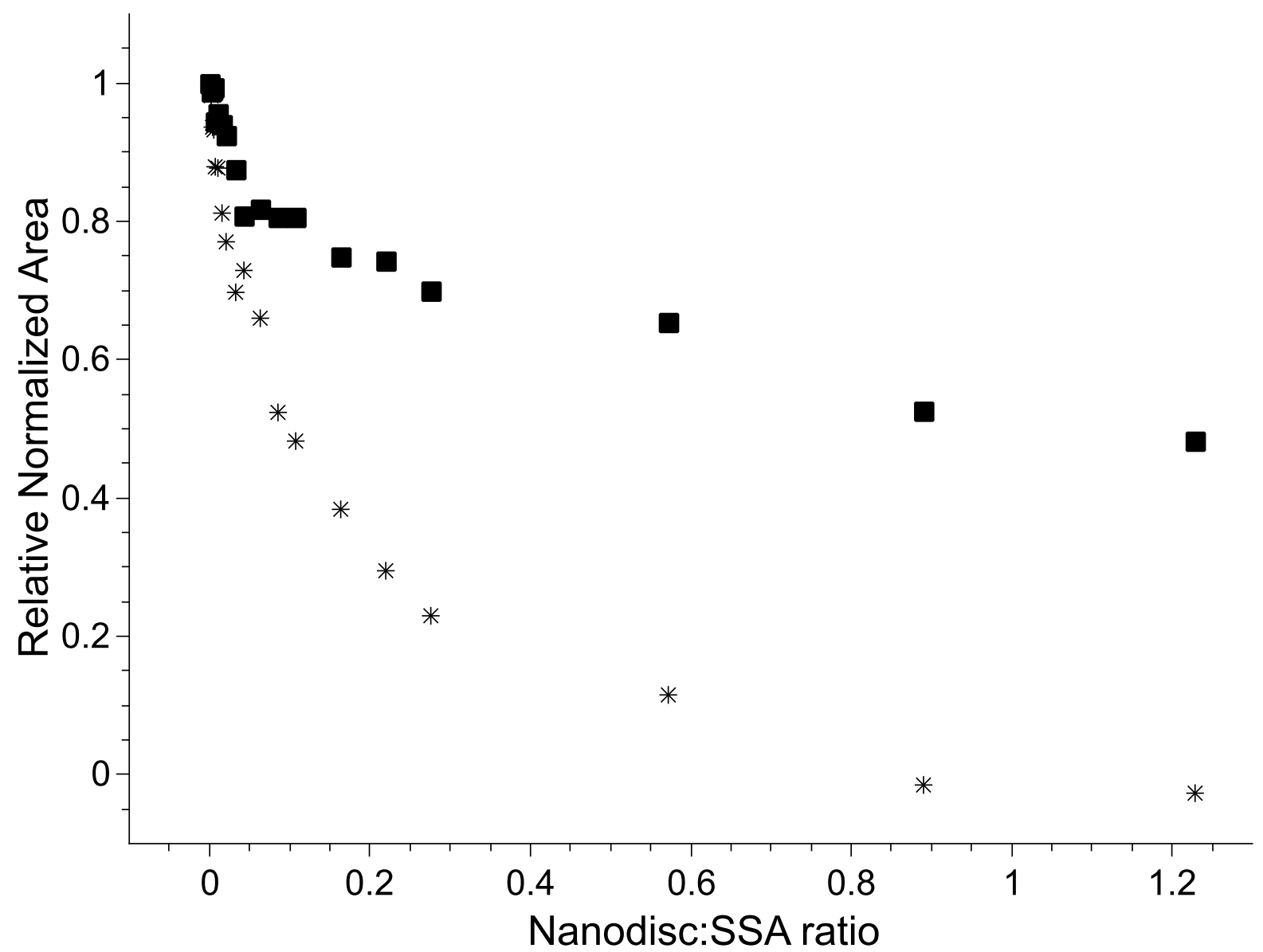

Figure S41 - The relative normalized area of the most downfield aromatic SSA resonance of $\mathbf{3}$ (filled squares) and its associated TBA cation (stars) upon titration with DMPC nanodiscs. 


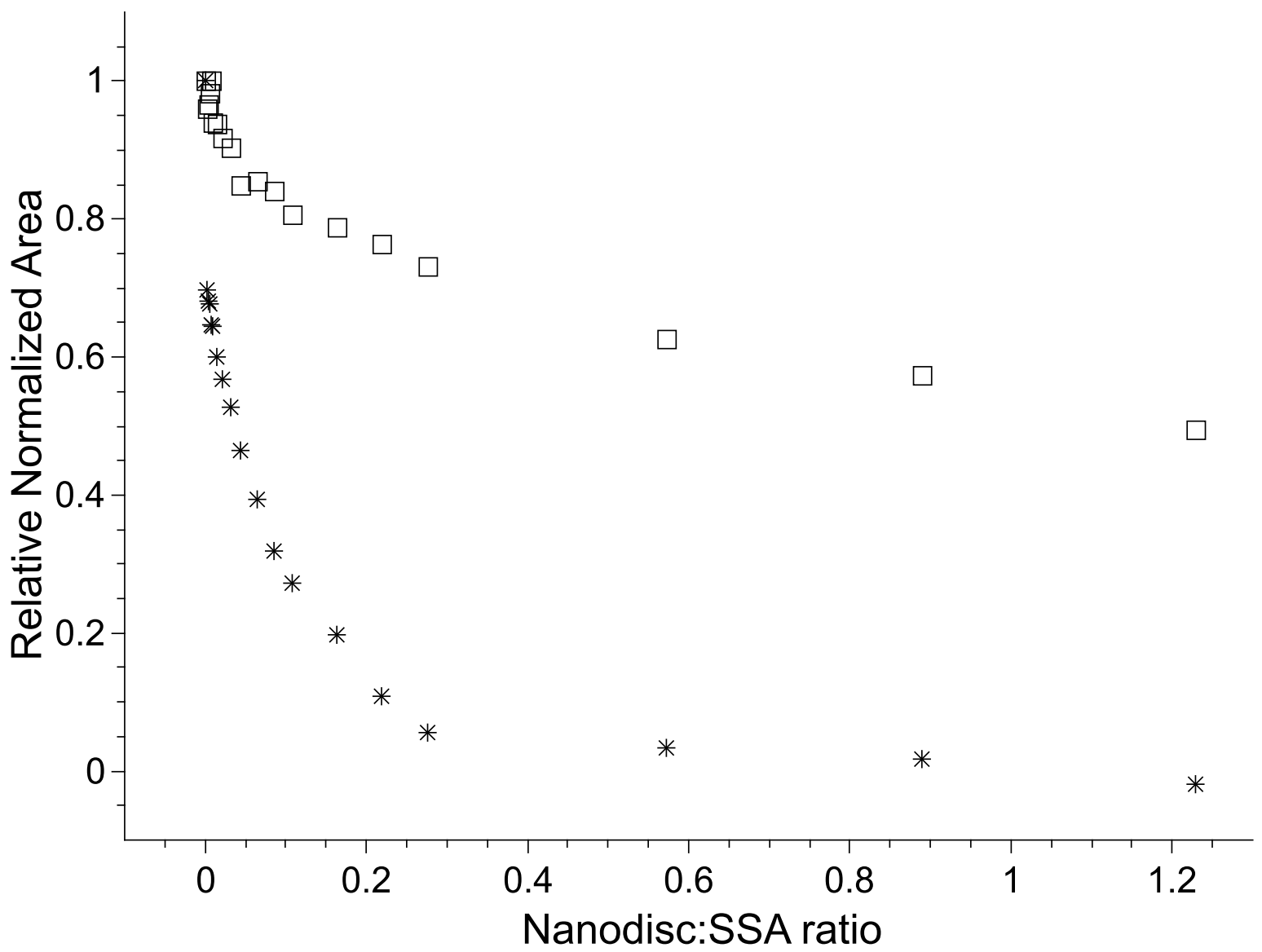

Figure S42 - The relative normalized area of the most downfield aromatic SSA resonance of 3 (open squares) and its associated TBA cation (stars) upon titration with E. coli nanodiscs. 


\section{References}

1. L. J. White, N. J. Wells, L. R. Blackholly, H. J. Shepherd, B. Wilson, G. P. Bustone, T. J. Runacres and J. R. Hiscock, Chem. Sci., 2017, 8, 7620-7630.

2. J. R. Hiscock, G. P. Bustone, B. Wilson, K. E. Belsey and L. R. Blackholly, Soft Matter, 2016, 12, 4221-4228.

3. H. Y. Carr and E. M. Purcell, Phys. Rev. , 1954, 94, 630-638.

4. S. Meiboom and D. Gill, Rev. Sci. Instrum., 1958, 29, 688-691. 